Please do not remove this page

RMIT

UNIVERSITY

\title{
An Analysis of the Tensile Deformation Behavior of Commercial Die-Cast Magnesium-Aluminum-Based Alloys
}

Ang, Hua Qian; Abbott, Trevor; Zhu, Suming; Easton, Mark

https://researchrepository.rmit.edu.au/esploro/outputs/9921861005801341/filesAndLinks?institution=61RMIT_INST\&index=null

Ang, H. Q., Abbott, T., Zhu, S., \& Easton, M. (2019). An Analysis of the Tensile Deformation Behavior of Commercial Die-Cast Magnesium-Aluminum-Based Alloys. Metallurgical and Materials Transactions A: Physical Metallurgy and Materials Science, 50(8), 3827-3841. https://doi.org/10.1007/s11661-019-05282-1 Document Version: Accepted Manuscript

Published Version: https://doi.org/10.1007/s11661-019-05282-1

Repository homepage: https://researchrepository.rmit.edu.au

(c) The Minerals, Metals \& Materials Society and ASM International 2019

Downloaded On 2023/04/26 17:20:17 +1000 


\title{
1 An analysis of the tensile deformation behavior of commercial die- 2 cast magnesium-aluminium based alloys
} \\ Hua Qian Anga ${ }^{\mathrm{a}}$ Trevor B. Abbott ${ }^{\mathrm{a}, \mathrm{b}}$, Suming Zhu ${ }^{\mathrm{a}}$, Mark A. Easton ${ }^{\mathrm{a}, *}$ \\ ${ }^{a}$ School of Engineering, RMIT University, Bundoora, Victoria 3083, Australia \\ ${ }^{b}$ Magontec Limited, Sydney, New South Wales 2000, Australia
}

7

8

Magnesium and its alloys have a complex progression of deformation mechanisms due to the hexagonal closed-packed crystal structure. Magnesium undergoes a series of different deformation modes as stress increases. The deformation behavior is marked by the commencement of elastic (Stage I), followed by <a b basal slip and twinning (Stage II), <a> prismatic slip (Stage III) and finally $\langle\mathrm{c}+\mathrm{a}>$ pyramidal slip (Stage IV). In this study, the deformation behavior of a range of commercial die-cast magnesium-aluminium based alloys are analyzed. Four distinct stages of strain hardening can be seen in the tensile stress-strain curve and these are modelled according to the assumption that they correspond to the four deformation mechanisms. It is shown that both Stages I and III can be described by a linear equation while Stages II and IV follow a power-law relationship and fitted with Hollomon's equation. A semi-empirical equation is proposed to model the entire stress-strain curve, which provides a simple way to understand the deformation of magnesium alloys and points towards better methods of modelling magnesium alloy behavior in part design.

Keywords: Magnesium alloys; Stress-strain curve; Plasticity; Dislocations; Twinning; Strainrate sensitivity

* Corresponding author. Tel: +61399256278

E-mail address: mark.easton@ rmit.edu.au 


\section{Introduction}

Die-cast magnesium $(\mathrm{Mg})$ alloys have low density and high specific strength and have found many applications in automotive structural parts, for example, AZ91 (Mg-9Al-1Zn) in steering column brackets and brake pedals, AM40 (Mg-4Al-0.3Mn) and AM60 (Mg-6Al$0.3 \mathrm{Mn}$ ) in seat frames and instrument panels, and AE44 (Mg-4Al-4RE) in an automotive front engine cradle [1-3]. A good knowledge of deformation behavior, especially strain-rate sensitivity is important for understanding the crashworthiness of these alloys.

Recently, the effect of strain rate on the tensile properties [4] and deformation behavior $[5,6]$ of similar die-casting alloys has been studied by the present authors at strain-rate range $10^{-6}-10^{-1} \mathrm{~s}^{-1}$. It is observed that the tensile deformation behavior of $\mathrm{Mg}$ and alloys can be separated into three regions: elastic, anelastic and plastic [7-11]. Within these regions, the stress-strain curve exhibits four distinct stages of strain hardening. Inspired by the KocksMecking theory of strain hardening [12, 13], which is also reported in [14-17] for $\mathrm{Mg}$ and alloys, an idea is generated that the four distinct stages of strain hardening in $\mathrm{Mg}$ and alloys can be characterized by the differences in deformation mechanisms as explained here.

Stage I - Elastic deformation is a reversible process which involves stretching of the atomic bonds. The elastic limit of $\mathrm{Mg}$ and alloys is relatively low (<40 MPa), with a consequently short linear region [7, 18].

Stage II - Beyond the elastic deformation is the onset of anelasticity and plasticity. During this stage, grains with a favorable orientation to the stress axis (soft-oriented grains) deform first via $<a>$ basal slip until they are stopped by obstacles, i.e. grain boundaries, while grains with harder orientations either remain elastic or twin [19]. As soft-oriented grains diminish their share of elastic strain, hard-oriented grains compensate by becoming more highly stressed. The overall hardening rate in this stage is determined by load sharing between soft and hardoriented grains [20]. <a> Basal slip induces plasticity while reversible twinning contributes to anelasticity [21]. Due to the limited independent <a> basal slip systems in $\mathrm{Mg}$ [22], twinning is essential to deformation in this region. The anelastic deformation in this stage is reported to be greater than plastic deformation, for example in die-cast AZ91 [8], AM60 and AE44 [5].

Stage III - As deformation continues at a higher stress level, the first available non-basal slip system, i.e. $<a>$ prismatic slip [19, 23-25] will be activated. In this stage, a combination of $<a>$ prismatic slip and $<a>$ basal slip offers only four independent slip systems [22] and this still does not satisfy the Von Mises-Taylor criterion [26, 27], therefore, twinning must still be present in this stage. Activation of $\langle a>$ prismatic slip allows the $<a>$ basal dislocations which were retarded by obstacles in the previous stage to cross slip (change of slip plane from basal to prismatic) to bypass obstacles, creating a forest of dislocations. The strain hardening rate in this stage drops to about $1.4 \mathrm{GPa}$ for pure $\mathrm{Mg}$, a value consistent with athermal accumulation of forest dislocations [13, 17, 28].

Stage IV - The end of Stage III is marked by onset of a second non-basal slip system, which experiments show is $\langle c+a\rangle$ pyramidal slip [29]. Activation of $\langle c+a\rangle$ pyramidal slip reduces the pile-up stresses (back stresses) at obstacles as dislocations piled up at obstacles in previous deformation stages are allowed to escape. This is also known as dynamic recovery $[17,30]$ which further reduces the strain hardening rate until fracture occurs. 
Note that the notion of different stages of deformation behavior is actually referring to the different dominant mechanisms (i.e. bond stretching, <a> basal slip, twinning and untwinning, $<a>$ prismatic and $<\mathrm{c}+\mathrm{a}>$ pyramidal slip), and the deformation mechanisms in previous stages may continue as the next stage commences. It should also be noted that these are generalizations as other factors such as inhomogeneous grain distributions and localized areas of high stress, i.e. near grain boundaries, will lead to localized early onset of the next deformation stage. In this paper, it is assumed that each stage begins when each deformation mode becomes extensive.

The strain hardening response due to these four deformation modes, <a> basal slip, extension twinning, $\langle a>$ prismatic slip and $\langle\mathrm{c}+\mathrm{a}>$ pyramidal slip [14, 17, 20, 25, 31-40] has been extensively studied in $\mathrm{Mg}$ and alloys by constitutive modelling. Some of these constitutive models were later extended to include untwinning [24, 41-45]. Extension twinning results in an $86.3^{\circ}$ reorientation of the basal pole, and untwinning will occur in a twin if the load is reversed [46]. It should be pointed out that most of these published studies have focused on developing crystal plasticity models and whilst their crystal plasticity models have also permitted the prediction of the stress-strain curve with reasonable success; crystal plasticity models are complex and can be computationally intensive.

Furthermore, there are also limitations to some of these models, for example, the model developed for $\{10 \overline{1} 2\}$ twinning [47] in an extruded AZ31 can predict the stress-strain curve at low strains, up to $1.5 \%$. However, the model is not able to extend to higher strains due to complex phenomena involved such as interactions between slip and twinning and saturation of twin nucleation at higher strains. In the modelling of Mg alloy AZ31 sheet [38], a power law was proposed to express tensile stress as a function of strain, strain rate and temperature. However, their proposed equation is only valid between $5-7 \%$ strain for strain rates of $10^{-2}-10^{0}$ $\mathrm{s}^{-1}$ and temperatures of 423-573 K. Their model does not provide a good fit at the early stages of deformation. The strain hardening model proposed in [25] is applied to the late stage of deformation (deformation regime following primary basal glide); extension twinning and $\langle\mathrm{a}>$ basal slip were assumed to be negligible and were not included in the model. Applying the Kocks-Mecking method of analysis [13, 48], Cáceres and his co-workers have analyzed the Stage III deformation of permanent mould-cast pure Mg [17] and die-cast Mg-9Al alloy [14] with a simple linear equation, but other stages of deformation were not investigated.

The purpose of this work is two-fold: develop a simpler analytical description to capture the multi-staged tensile stress-strain curve and, in the process, increase the understanding of the development of different slip and twinning modes in a range of die-cast $\mathrm{Mg}$-Al based alloys with various $\mathrm{Al}$ contents, i.e. AM40, AM60, AZ91 and AE44 at a wide strain-rate range 10-6 $10^{-1}$. These alloys are the most widely used commercial alloys. Apart from their commercial importance, these alloys were selected to understand the deformation behavior of high-strength alloys (AZ91 and AE44-T5) and medium-strength alloys (AM40, AM60 and AE44). Decomposition of the stress-strain curve into different stages and analyzing them individually provides insights into the contribution of each deformation mechanism and this will provide the foundation for future development of improved structural alloys. This paper is structured as follows: the stress-strain curve is first decomposed into four stages of deformation and then reconstructed with a simple analytical equation and this is followed by model validation and a brief discussion on the applicability of the current approach. 


\section{Materials and Experimental Details}

\subsection{Materials}

Commercial high-pressure die-cast AM40, AM60, AZ91 and AE44 alloys of similar grain sizes $(\sim 8 \mu \mathrm{m})$ were used in this study. Details of the casting procedure can be found elsewhere [49]. The chemical compositions of these alloys analyzed using inductively coupled plasma atomic emission spectroscopy (ICP-AES) are listed in other publications by the authors $[4,5]$. Some AE44 specimens were also given an ageing treatment for $32 \mathrm{~h}$ at $200{ }^{\circ} \mathrm{C}$ (labelled T5).

\subsection{Mechanical Testing}

Dog-bone-shaped round samples, $100 \mathrm{~mm}$ in length with a $36 \mathrm{~mm}$ parallel section in the gauge length and a diameter of $5.6 \mathrm{~mm}$ were used in this study. Monotonic and cyclic tension loading-unloading tests were performed on an Instron 5569 universal testing machine with a $50 \mathrm{kN}$ load cell at room temperature using a constant rate of crosshead displacement with nominal strain rates in the range from $10^{-6}$ to $10^{-1} \mathrm{~s}^{-1}$. A $25 \mathrm{~mm}$ gauge length extensometer was attached to the specimen and digital output files of the flow curves were converted to stress-strain curves. For the cyclic loading-unloading tests, the samples were loaded to a predetermined strain, unloaded to zero stress and then reloaded again. All alloys were cyclic tested to a strain of 0.03, except AZ91; AZ91 was tested to a higher strain (0.045) to obtain the maximum anelasticity. Each test was repeated three times. Compression tests were not conducted in this study as high-pressure die-cast alloys are relatively isotropic in mechanical properties [50].

\section{Results}

\subsection{Stress-Strain Curves}

Fig. 1 shows the monotonic (taken from [4]) and cyclic stress-strain curves at different strain rates for AZ91 and AE44 (alloys with the most different behavior observed in these experiments). The flow curves of as-cast AE44 consistently shift higher with increasing strain rate while the changes in the flow curves of AZ91 are smaller. It should be noted that the flow curves of aged AE44-T5 show slightly higher strain-rate dependence than that of AE44, while the flow curves of AM40 and AM60 are like AZ91, show a much-reduced effect of strain rate under both monotonic and cyclic testing. The original paper [4] showed that the reduction in strain-rate sensitivity with increasing $\mathrm{Al}$ contents in solution was due to dynamic strain aging from the interaction between Al solute and dislocations. As also reported [4], both AE44 and AE44-T5 have very little Al solute in the $\alpha-\mathrm{Mg}$ matrix, especially in the T5 condition where even more solute is removed as a result of precipitation [51], and therefore they are less likely to be affected by dynamic strain aging and the intrinsic strain-rate sensitivity in $\mathrm{Mg}$ attributed to its hexagonal closed-packed crystal structure [52] is observed. Cycling does not affect the strain hardening behavior as monotonic flow curve (dashed line) follows closely with the cyclic one. 
160
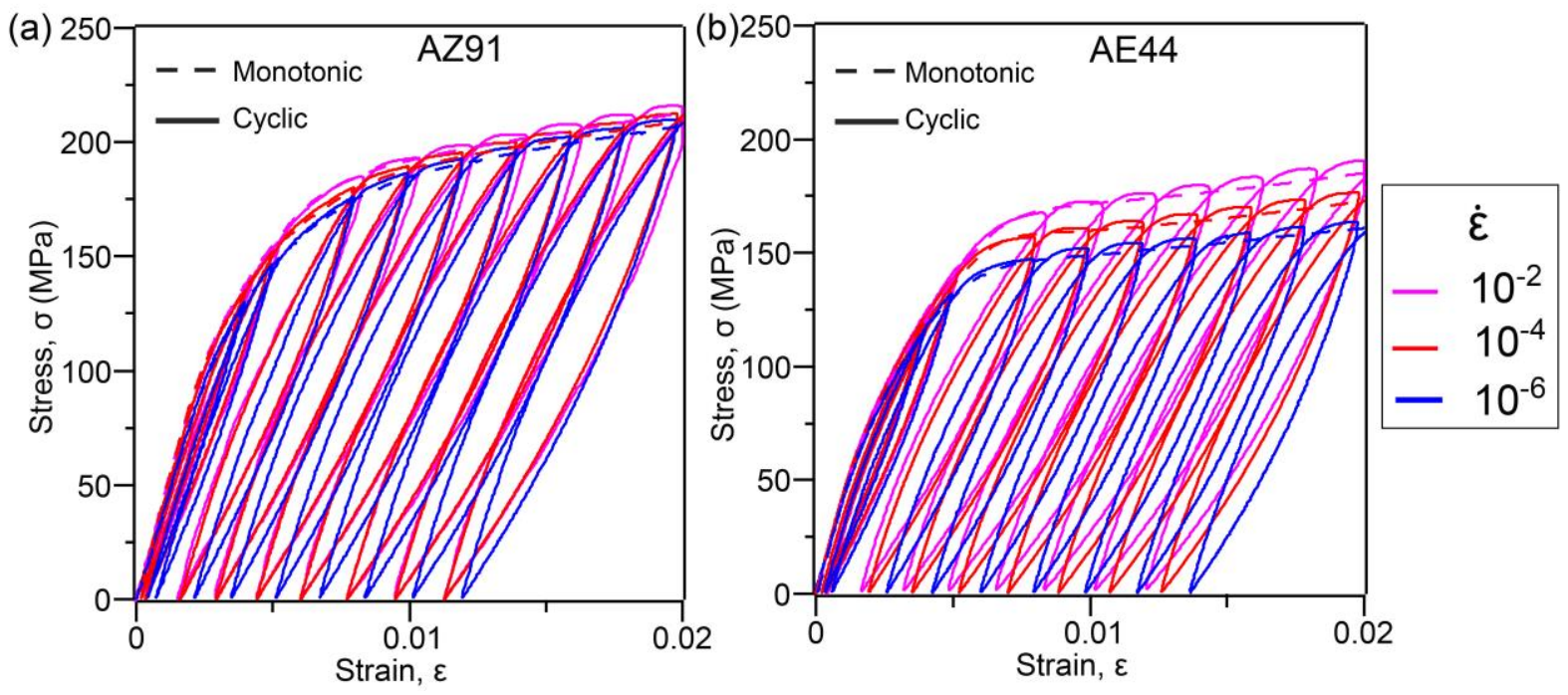

Fig. 1. Monotonic (dashed) taken from [4] and cyclic (solid) stress-strain behavior of (a) AZ91 and (b) AE44 at different strain rates, $\dot{\varepsilon}=10^{-6} \mathrm{~s}^{-1}$ (top curve) $-10^{-2} \mathrm{~s}^{-1}$ (bottom curve) .

\subsection{Analysis of Stress-Strain Curve}

The analysis approach in this section decomposes the stress-strain curve into four stages of deformation described in the Introduction and quantifies each stage of strain (Stage I strain, $\varepsilon_{\mathrm{I}}$; Stage II strain, $\varepsilon_{\mathrm{II}}$; Stage III strain, $\varepsilon_{\mathrm{III}}$; Stage IV strain, $\left.\varepsilon_{\text {IV }}\right)$ individually. To undertake this analysis, each time when a new stage of deformation is being analyzed, previous stages are removed from the stress-strain curve and are not included in the analysis. By deconstructing the stress-strain curve in this way, the total strain, $\varepsilon_{\mathrm{t}}$ can then be determined by the summation of these individual stage of strains:

$$
\varepsilon_{\mathrm{t}}=\varepsilon_{\mathrm{I}}+\varepsilon_{\mathrm{II}}+\varepsilon_{\mathrm{III}}+\varepsilon_{\mathrm{IV}}
$$

Consequently, in this section the stress-strain curve is deconstructed to understand the different stages of deformation and then reconstructed into an analytical description of the stress-strain curve.

\subsubsection{Stage I: Elasticity}

Elastic deformation is well understood as a change in shape of a material at low stress that is recoverable after the applied stress is removed. In this stage, the applied stress, $\sigma$, is proportional to elastic strain, $\varepsilon_{\mathrm{I}}$, and the deformation behavior is governed by Hooke's law:

$$
\sigma=\mathrm{E} \varepsilon_{\mathrm{I}}
$$

For $\mathrm{Mg}$ and alloys, the stress-strain curve has very small linear elastic region which applies only at low stress levels (<40MPa) [7, 10,11,18], where the elastic modulus of $\mathrm{Mg}, \mathrm{E}=45$ $\mathrm{GPa}[2,53]$ is measured. 


\subsubsection{Stage II: $\langle a\rangle$ Basal Slip and Twinning}

The departure of linear elasticity is marked by the onset of anelastic and plastic deformations. During this stage, soft-oriented grains will undergo plastic deformation first by $<a>$ basal slip. However, due to the hexagonal closed-packed crystal structure of $\mathrm{Mg}$ and alloys, $<$ a $>$ basal slip provides only two independent slip systems [22] and this does not satisfy the von Mises-Taylor criterion [26, 27] for homogeneous deformation. Therefore, most grains in this region will undergo twinning [54-56]. However, twins formed during loading are not stable [57]; and they can revert during unloading [58], giving rise to large hysteresis loops as observed in cyclic stress-strain curves (Fig. 1). The anelastic strain is measured from the width of these hysteresis loops $[8,10,18]$. Therefore, this stage is a mix of anelasticity and plasticity. For the sake of the following discussion, the term anelastic strain, $\varepsilon_{\mathrm{ae}}$ is associated only with reversible twinning (untwinning); while Stage II strain, $\varepsilon_{\text {II }}$ is made up of anelasticity and plasticity, and is composed of all three mechanisms, <a> basal slip, irreversible twinning and reversible twinning.

To examine the relationship between $\varepsilon_{\mathrm{II}}$ and $\varepsilon_{\mathrm{ae}}, \varepsilon_{\mathrm{t}}-\varepsilon_{\mathrm{I}}$ taken from monotonic flow curve and $\varepsilon_{\mathrm{ae}}$ taken from hysteresis loops in cyclic flow curve are plotted in Fig. 2. Note that at such low strains of $\leq 0.005, \varepsilon_{\text {III }}$ and $\varepsilon_{\text {IV }}$ are negligible. The average of the flow curve is plotted as dashed line and it is named $\varepsilon_{\mathrm{II}, \mathrm{av}}$. It is clear that $\varepsilon_{\mathrm{ae}}$ (dotted) is proportional to $\varepsilon_{\mathrm{II}, \mathrm{av}}$ (dashed) and $\varepsilon_{\mathrm{II}, \mathrm{av}}$ is composed of $60-75 \%$ of $\varepsilon_{\mathrm{ae}}$ depending on the alloy. In short, twinning dominates in Stage II and most twins that form revert upon unloading, correlating well with the literature for fine-grained high-pressure die-cast $\mathrm{Mg}$ alloys [8, 9].

It is observed that $\varepsilon_{\mathrm{ae}}$ is insensitive to strain rate prior to reaching the maximum value. This is because at early stages of deformation when <a> prismatic slip is absent, deformation is controlled by <a> basal slip and twinning which are less strain-rate sensitive [35, 59-62]. As deformation continues, anelasticity begins to saturate to a maximum upon extensive activation of $\langle\mathrm{a}\rangle$ prismatic slip. The strain-rate sensitivity of $\langle\mathrm{a}\rangle$ prismatic slip [59, 61] leads immediately to the high strain-rate dependence of maximum anelastic strain [5].

Since $\varepsilon_{\mathrm{II}, \text { av }}$ is made up of $60-75 \%$ of $\varepsilon_{\mathrm{ae}}$ (reversible twinning) (Fig. 2), both irreversible twinning and slip mechanisms must contribute to the rest of the strain magnitude. Irreversible twinning fraction was observed to be less than $10 \%$ of the deformation in these die-cast alloys [4], a simple assumption is made that $\varepsilon_{\text {II }}$ can be modelled like $\varepsilon_{\mathrm{ae}}$, being strain-rate insensitive at early stages of deformation prior to reaching a maximum. 

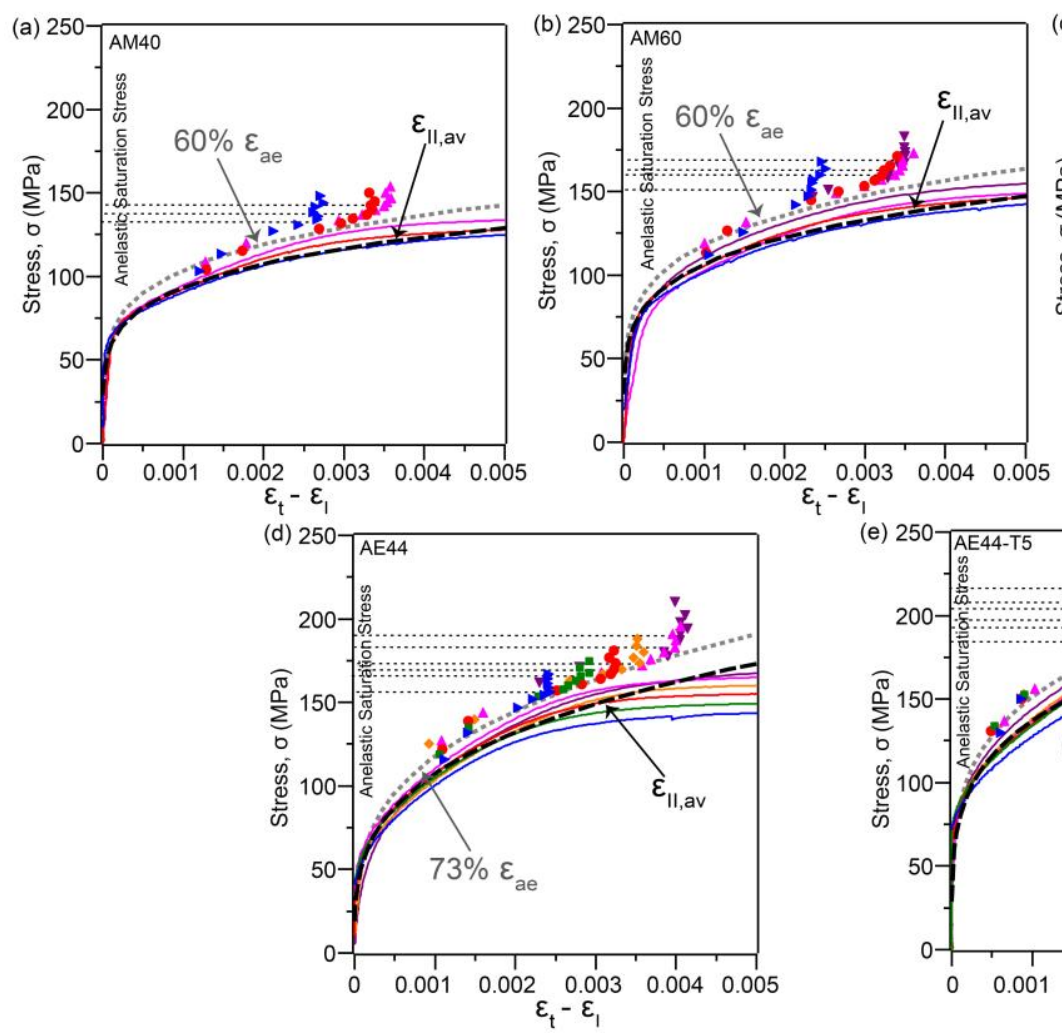

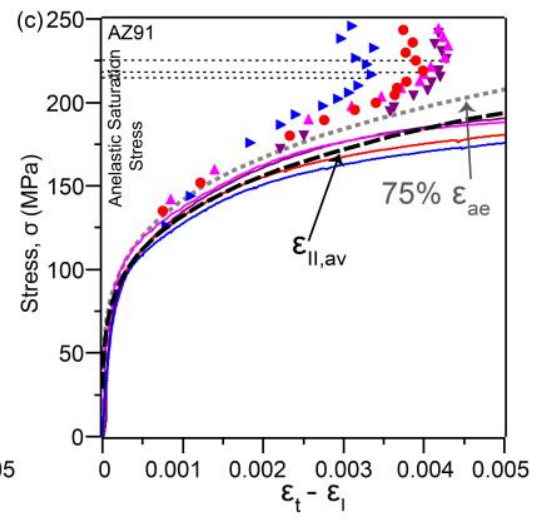

(e)
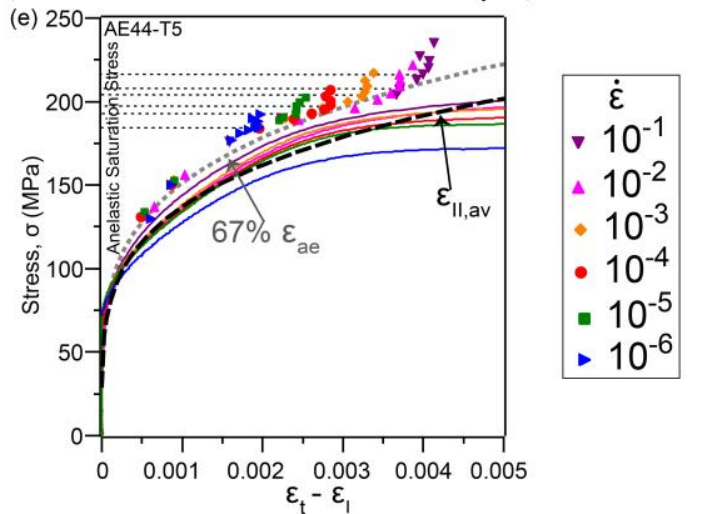

Fig. 2. The applied stress as a function of $\varepsilon_{t}-\varepsilon_{I}$ strain, for (a) AM40, (b) AM60, (c) AZ91, (d) AE44 and (e) AE44-T5, at strain-rate range $10^{-6}-10^{-1} \mathrm{~s}^{-1}$. The dotted line is the anelastic strain, $\varepsilon_{\mathrm{ae}}$ and the dashed line represents the average of Stage II strain $\varepsilon_{\mathrm{II}, \mathrm{av}}$ which is composed of $60-75 \%$ of anelastic strain. Note that $\varepsilon_{\mathrm{III}}$ and $\varepsilon_{\mathrm{IV}}$ are negligible at such low strains.

Modelling of Stage II deformation has not yet been reported but anelasticity which follows the same trend as Stage II has been modelled with a Weibull function because of its sigmoidal relationship with applied stress [9]:

$$
\varepsilon_{\mathrm{ae}}=\varepsilon_{\mathrm{ae}, \max }\left[1-\exp \left\{-\left(\frac{\sigma}{\sigma_{1}}\right)^{\mathrm{m}_{\mathrm{e}}}\right\}\right]
$$

where $\varepsilon_{\mathrm{ae}, \max }$ is the maximum anelastic strain, $\sigma_{1}$ is the stress where anelasticity increases the fastest and $\mathrm{m}_{\mathrm{e}}$ is the Weibull modulus. However, anelasticity can be further divided into strain-rate insensitive and sensitive components as observed in Fig. 2. The Weibull function cannot clearly reflect these two distinct regions of anelasticity because any changes to the Weibull function parameters change the entire function curve and not just the maximum. This is illustrated in Fig. 3(a) using the $\varepsilon_{\mathrm{ae}}$ measured from AE44 at $10^{-4} \mathrm{~s}^{-1}$ as an example. In contrast, Fig. 3(b) shows that a much simpler power-law relationship is able to model the strainrate insensitive component of the anelasticity while the strain-rate sensitive component (maximum anelastic strain) can be included in the modelling of Stage III deformation as discussed in Section 3.2.3. 

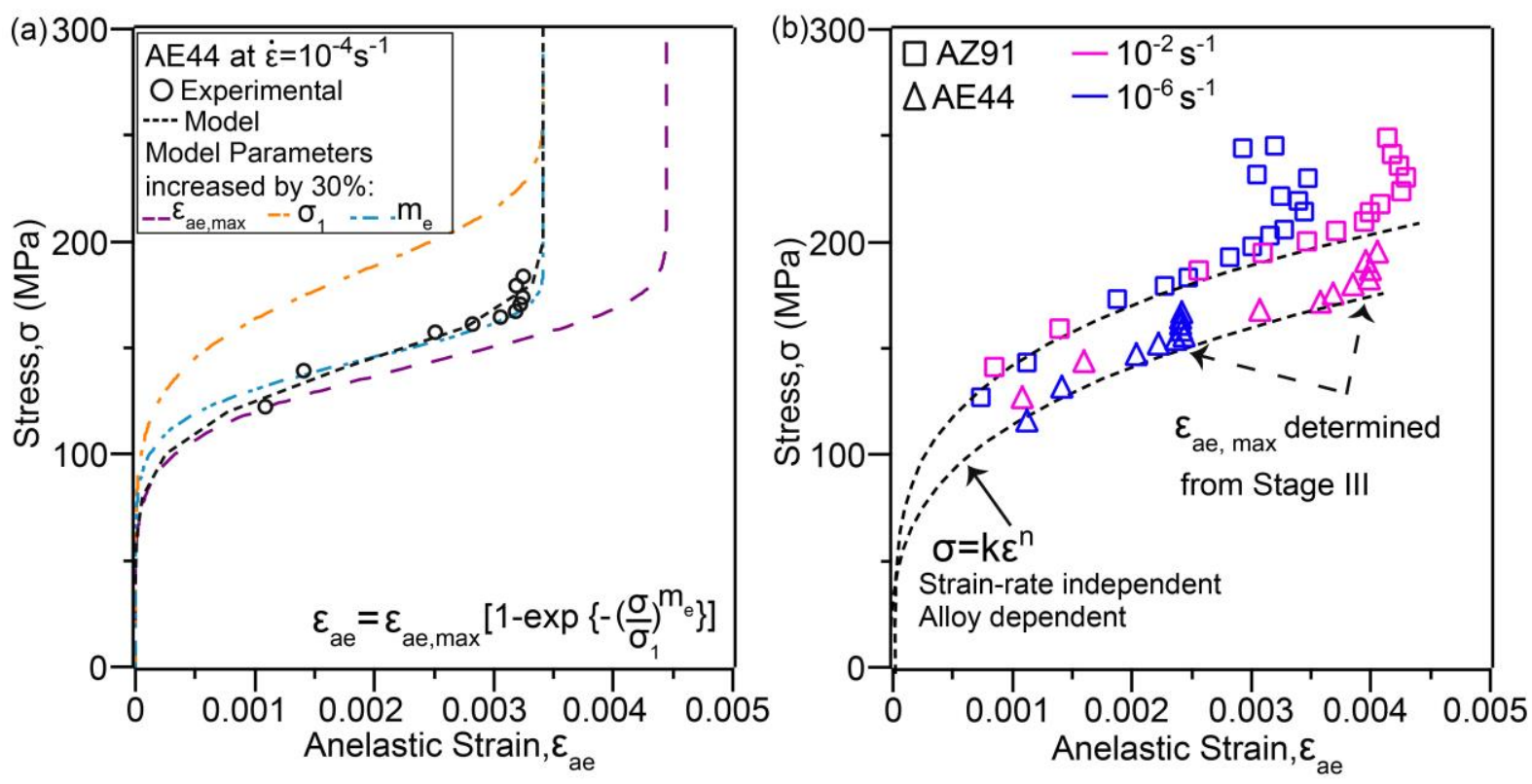

Fig. 3. Comparison of (a) the Weibull function [9] and (b) the power-law function in analyzing the stress-anelastic strain relationship in Stage II. Changing the Weibull function parameters is shown to alter the entire function curve, which cannot reflect the strain-rate insensitive and sensitive components of anelasticity.

Due to this dilemma, we suggest modelling the strain-rate insensitive component of Stage

$$
\sigma=K_{\text {II }} \varepsilon_{\text {II }}^{n_{I I}}
$$

where $\mathrm{K}_{\mathrm{II}}$ is the strength coefficient and $\mathrm{n}_{\mathrm{II}}$ is the strain hardening exponent in Stage II. The next step is to determine the upper limit of Eq. (4) to describe the observed strain-rate sensitivity of the maximum anelasticity.

To find this upper limit, the strain-rate sensitive maximum anelasticity needs to be reviewed. Based on our observation in our recent publication [5], there is a correlation between maximum anelastic stress, $\sigma_{\mathrm{ae} \text {,max }}$ and the stress when Stage III strain reaches 0.01 (for AM40, AM60, AE44) and 0.015 (for AZ91) as shown in Fig. 4. $\sigma_{0.01, \text { III }}$ and $\sigma_{0.015, \text { III }}$ denote the stresses when Stage III strain (also known as $\left\langle\right.$ a > prismatic strain), $\varepsilon_{\text {III }}$, reaches 0.01 and 0.015 , respectively. Unlike the rest of the alloys, $\sigma_{0.01, \text { III }}$ in AZ91 does not match its $\sigma_{\mathrm{ae} \text {,max }}$ (symbol deviates from dashed line), indicating that the maximum anelasticity in AZ91 saturates at a higher $\varepsilon_{\text {III }}$ of 0.015. Determination of $\varepsilon_{\text {III }}$ is covered in Section 3.2.3. 


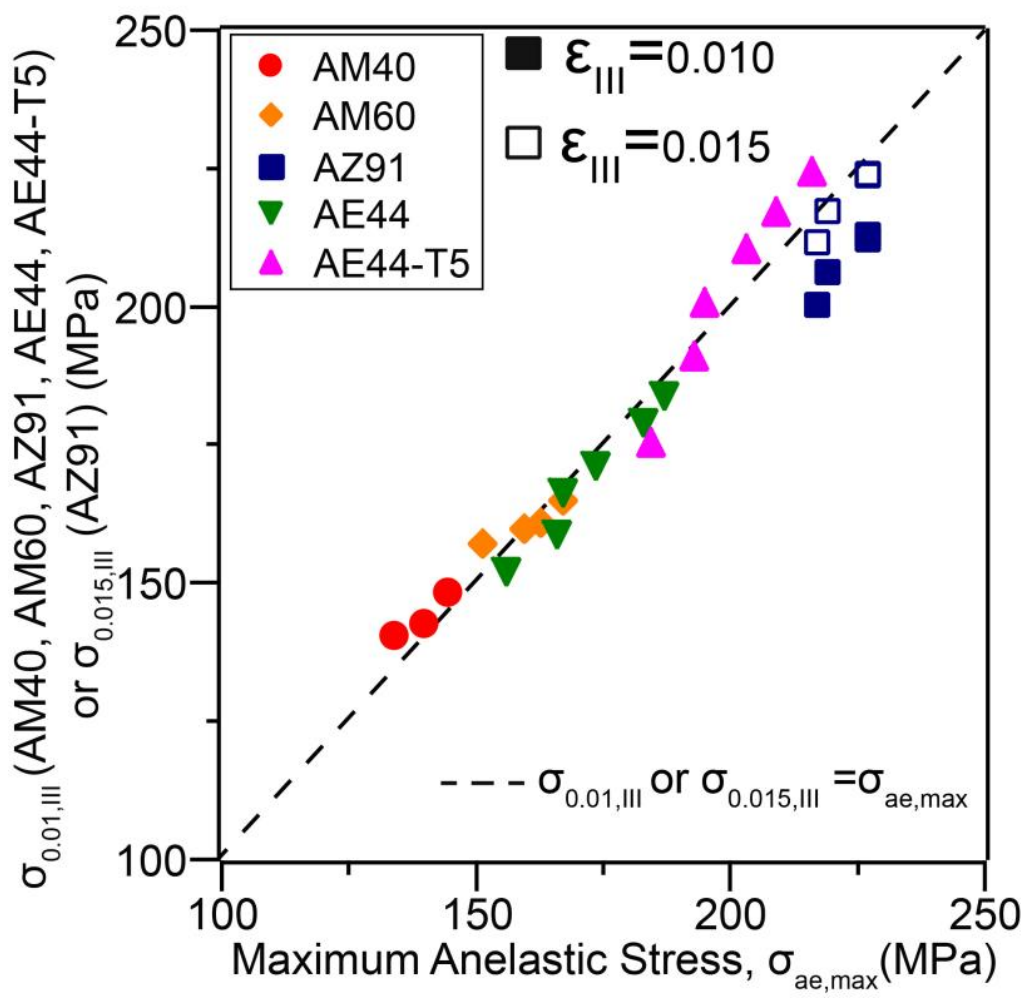

Fig. 4. Stress when $\varepsilon_{\text {III }}$ reaches 0.01 for AM40, AM60, AZ91, AE44 and AE44-T5 and 0.015 for AZ91 as a function of maximum anelastic stress.

The observation that anelasticity reaches a maximum at $\varepsilon_{\text {III }}$ of $\sim 0.01-0.015$ is consistent with other work. Previous experiments showed that maximum anelasticity occurred at a plastic strain of $\sim 0.01$ for mold-cast Mg-Gd alloys [11], 0.015 for sand-cast pure $\mathrm{Mg}$ and $\mathrm{Mg}-\mathrm{Zn}$ alloys [9] and die-cast AZ91 [8], 0.02 for cast Mg-Al alloys [63, 64]. When deformation is small, less than a strain of 0.01, twins can multiply undisturbed, and anelasticity increases with stress and strain. When deformation is large, exceeding a strain of 0.01 , activation of other slip systems, such as $<a>$ prismatic slip, in the matrix surrounding the twins will decrease the twin boundary mobility. Consequently, reversible twinning is restricted $[65,66]$. Considering this information, an assumption is made that Stage II saturates (due to saturation of reversible twinning) when anelasticity reaches a maximum upon extensive activation of $\langle a>$ prismatic slip at $\varepsilon_{\text {III }}$ of 0.01 for AM40, AM60 and AE44 and 0.015 for AZ91.

With this assumption in mind, Fig. 5 compares the experimental Stage II curves with those computed by Eq. (4) at low $\varepsilon_{\text {II }}$ of no more than 0.0015 for AZ91 and AE44. This low $\varepsilon_{\text {II value }}$ was chosen to ensure no involvement of $\langle a\rangle$ prismatic and $\langle c+a\rangle$ pyramidal slip in the modelling of Stage II. It is observed that Stage II starts at about $25 \mathrm{MPa}$ for AE44 and about $40 \mathrm{MPa}$ for AZ91 when $\varepsilon_{\mathrm{II}}$ becomes significant, indicating that AZ91 has a larger elastic region. The experimental flow curves (solid) in this stage show no strain-rate dependency. The slight difference between the flow curves is due to experimental variation, and an average flow curve (dashed) is fitted. The $\mathrm{K}_{\text {II }}$ and $\mathrm{n}_{\text {II }}$ values for each strain rate and alloy from repeated tests are summarized in Table 1. It is clear that Stage II parameters do not show systematic variations with strain rate, so the average values are used to model Stage II deformation. 


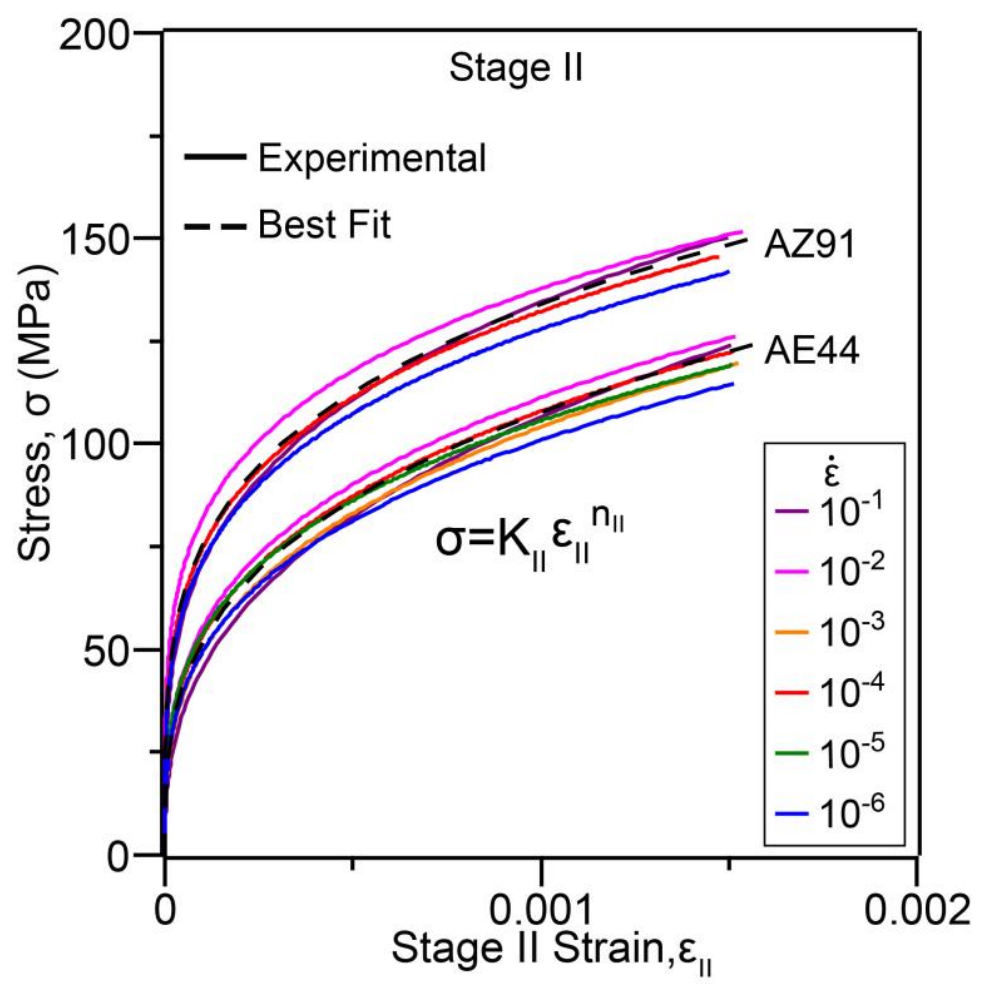

297 Fig. 5. The experimental stress-strain curves (solid) in Stage II for AZ91 and AE44, as 298 compared with the best fitted curves (dashed) using Eq. (4).

299

300 Table 1. Parameters in Stage II: $\mathrm{K}_{\mathrm{II}}(\mathrm{MPa})$ and $\mathrm{n}_{\mathrm{II}}$ of best fit of Eq. (4).

301

\begin{tabular}{|c|c|c|c|c|c|c|c|c|c|c|}
\hline$\dot{\varepsilon}$ & \multicolumn{2}{|c|}{ AM40 } & \multicolumn{2}{|c|}{ AM60 } & \multicolumn{2}{|c|}{ AZ91 } & \multicolumn{2}{|c|}{ AE44 } & \multicolumn{2}{|c|}{ AE44-T5 } \\
\hline $10^{-6}$ & $337 \pm 0.84$ & $0.19 \pm 0.00$ & $507 \pm 59.2$ & $0.23 \pm 0.02$ & $1049 \pm 316$ & $0.30 \pm 0.05$ & $794 \pm 61.7$ & $0.30 \pm 0.01$ & $565 \pm 42.9$ & $0.21 \pm 0.02$ \\
\hline $10^{-5}$ & - & - & - & - & - & - & $864 \pm 67.7$ & $0.30 \pm 0.01$ & $679 \pm 0.42$ & $0.23 \pm 0.00$ \\
\hline $10^{-4}$ & $411 \pm 31.6$ & $0.22 \pm 0.01$ & $455 \pm 1.50$ & $0.21 \pm 0.00$ & $591 \pm 148$ & $0.21 \pm 0.04$ & $955 \pm 59.7$ & $0.32 \pm 0.01$ & $714 \pm 25.4$ & $0.24 \pm 0.01$ \\
\hline $10^{-3}$ & - & - & - & - & - & - & $987 \pm 2.17$ & $0.33 \pm 0.00$ & $757 \pm 4.10$ & $0.25 \pm 0.00$ \\
\hline $10^{-1}$ & - & - & $638 \pm 2.32$ & $0.26 \pm 0.00$ & $916 \pm 0.07$ & $0.28 \pm 0.00$ & $1369 \pm 1.25$ & $0.37 \pm 0.00$ & $791 \pm 1.47$ & $0.25 \pm 0.00$ \\
\hline Average & $387 \pm 39.5$ & $0.21 \pm 0.01$ & $552 \pm 89$ & $0.24 \pm 0.02$ & $803 \pm 256$ & $0.25 \pm 0.05$ & $978 \pm 190$ & $0.32 \pm 0.02$ & $712 \pm 77.9$ & $0.24 \pm 0.01$ \\
\hline
\end{tabular}

302

303

304

305

306

307

308

309

310

311

\subsubsection{Stage III: $\langle a\rangle$ Prismatic}

The end of Stage II is determined by the onset of $<a>$ prismatic slip. In this stage, any $<a>$ basal plane dislocations inhibited by obstacles (e.g. grain boundaries) are allowed to cross slip, relaxing the dislocation pile-up stresses at grain boundaries. Activation of $\langle a\rangle$ prismatic slip allows cross slip to occur and creates a forest of dislocations in the process. The strain hardening rate in this stage is linear and follows an equation of the form $[13,17,30]$ :

$$
\sigma=\Theta \varepsilon_{\mathrm{III}}+\sigma_{\mathrm{y}, \mathrm{III}}
$$


where $\varepsilon_{\text {III }}$ is Stage III strain (<a> prismatic strain), $\sigma_{y, I I I}$ is the $<\mathrm{a}>$ prismatic yield stress at the start of $\varepsilon_{I I I}$, and $\Theta$ is the strain hardening rate in Stage III (slope), with the definition [13, 67]:

$$
\Theta=\Theta_{\mathrm{h}}-\Theta_{\mathrm{r}}(\dot{\varepsilon}, T)
$$

The first term $\Theta_{\mathrm{h}}$ is the athermal component of strain hardening rate which is between 1-2 $\mathrm{GPa}$ [17]. $\Theta_{\mathrm{h}}$ is $\approx \mathrm{E} / 32 \approx 1.4 \mathrm{GPa}$ for pure $\mathrm{Mg}$ [17] and $\mathrm{Mg}-9 \mathrm{Al}$ [14], and $\approx \mathrm{E} / 25 \approx 1.8 \mathrm{GPa}$ for AZ31 [15], where $\mathrm{E}$ is the elastic modulus of $\mathrm{Mg}$ (45 GPa [2]). $\Theta_{\mathrm{h}}$ is insensitive to many variables and it varies only slightly from one metal to another (within a factor of 2) [68, 69]. For face-centred cubic polycrystals [13], $\Theta_{\mathrm{h}} \approx \mathrm{E} / 50$.

The second term $\Theta_{\mathrm{r}}$ is the thermal component which describes the dynamic recovery rate. $\Theta_{\mathrm{r}}$ is both strain-rate and temperature dependent and it accounts for any softening effects due to dislocation annihilation as temperature $(T)$ increases and/or strain rate $(\dot{\varepsilon})$ decreases. At the limit of the highest strain rate or lowest temperature, $\Theta_{\mathrm{r}}$ approaches zero, and $\Theta=\Theta_{\mathrm{h}}$.

The modelling of $\Theta$ is not very well defined. Kocks and Mecking [13] defined $\Theta$ as

$$
\Theta=\Theta_{\mathrm{h}}\left(1-\frac{\sigma_{\mathrm{y}, \mathrm{III}} / \mu}{\mathrm{r}(\dot{\varepsilon}, T) \sigma_{\mathrm{y}, \mathrm{III}} / \mu_{0}}\right)
$$

and $\mathrm{r}$ :

$$
\mathrm{r}=\left\{1-\sqrt{\left(\frac{1}{\mathrm{~g}_{0}} \frac{\mathrm{kT}}{\mu \mathrm{b}^{3}} \ln \frac{\dot{\varepsilon}_{0}}{\dot{\varepsilon}}\right)}\right\}^{2}
$$

where $\sigma_{\mathrm{y}, \mathrm{III}}$ is a mechanical threshold ( $<\mathrm{a}>$ prismatic yield stress at $0 \mathrm{~K}$ ); $\mu$ is the shear modulus, $\mu_{0}$ is the shear modulus at $0 \mathrm{~K}$; $g_{0}$ is an extrapolated value from Fig. 26 in [13] with no identified physical meaning; $\mathrm{k}$ is the Boltzmann constant; $\mathrm{b}$ the magnitude of the Burgers vector of the dislocations and $\dot{\varepsilon}_{0}$ is a constant [13].

Here, by combining Eqs. (7) and (8), $\Theta$ is calculated using

$$
\Theta=\Theta_{\mathrm{h}}-\Theta_{\mathrm{h}} \frac{\mathrm{A}}{\left\{1-\sqrt{\mathrm{B} T \ln \left(\frac{\mathrm{C}}{\dot{\varepsilon}}\right)}\right\}^{2}}
$$

where A, B, C are grouped constants made up of individual functional dependence:

$$
\begin{aligned}
\mathrm{A} & =\frac{\sigma_{\mathrm{y}, \mathrm{III}} / \mu}{\sigma_{\mathrm{y}, \mathrm{III}} / \mu_{0}} \\
\mathrm{~B} & =\frac{1}{\mathrm{~g}_{0}} \frac{\mathrm{k}}{\mu \mathrm{b}^{3}} \\
\mathrm{C} & =\dot{\varepsilon}_{0}
\end{aligned}
$$

and $<\mathrm{a}>$ prismatic yield stress, $\sigma_{\mathrm{y}, \mathrm{III}}$ can be modelled using Eq. (13) as reported [67]: 


$$
\sigma_{\mathrm{y}, \mathrm{III}}=\sigma_{\mathrm{y}, \mathrm{III}}\left(\frac{\dot{\varepsilon}}{\dot{\varepsilon}_{0}}\right)^{\mathrm{n}}
$$

351

352

353

354

355

356

357

358

359

360

361

362

363

where $\mathrm{n}$ is the temperature dependent exponent, $\mathrm{n}=\frac{\mathrm{k} T}{\mu \mathrm{b}^{3}}$.

The straight lines (dashed) in Fig. 6 are the linear approximations of the experimental flow curves (solid), which follow Eq. (5). The measured values of $\Theta$ and $\sigma_{y, I I I}$ from two sets of data are summarized in Table 2.
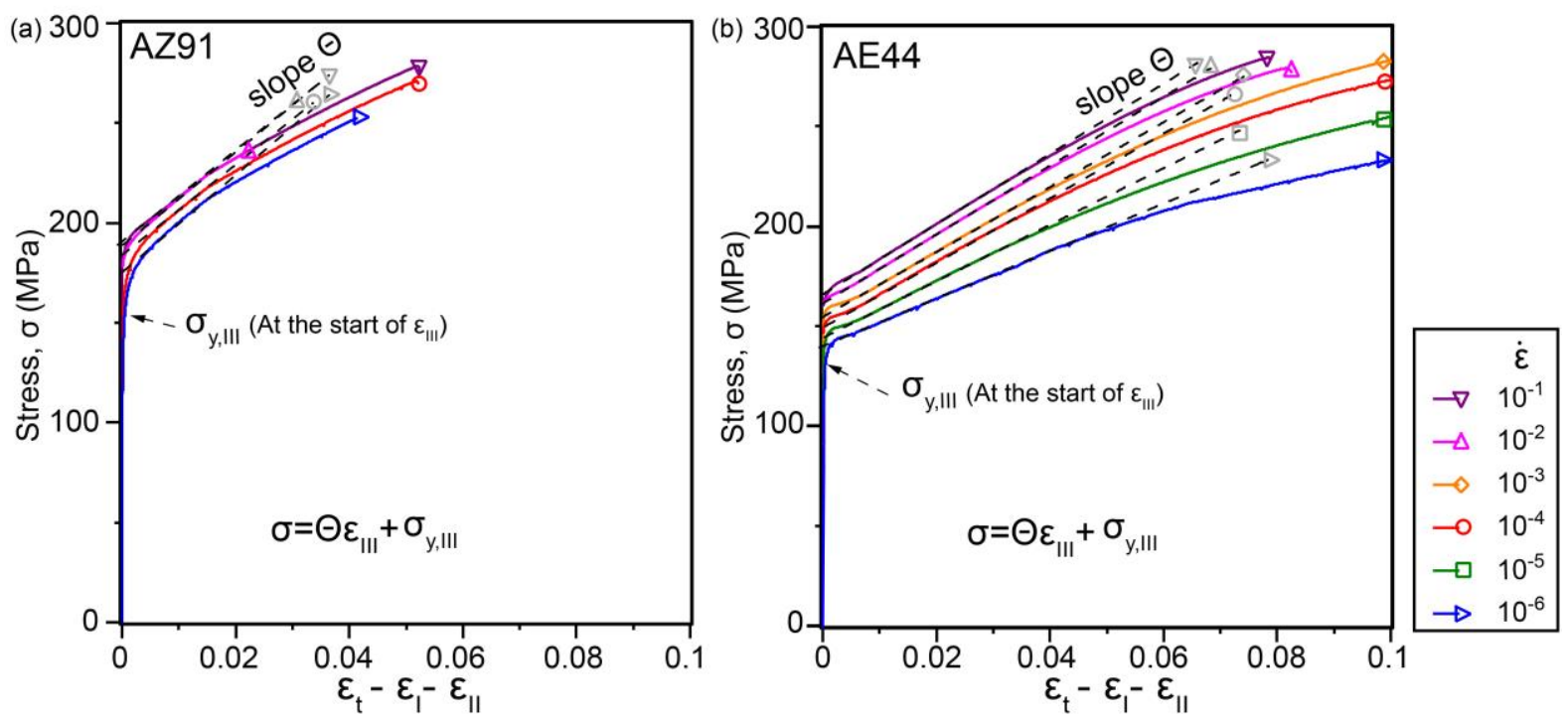

Fig. 6. The experimental flow curves (solid) of (a) AZ91 and (b) AE44 at strain rates $10^{-6}-10^{-1}$ $\mathrm{s}^{-1}$ as compared with the best fitted linear lines (dashed) according to Eq. (5).

\begin{tabular}{ccccccccccc}
\hline \multirow{2}{*}{$\dot{\boldsymbol{\varepsilon}}$} & \multicolumn{2}{c}{ AM40 } & \multicolumn{2}{c}{ AM60 } & \multicolumn{2}{c}{ AZ91 } & \multicolumn{2}{c}{ AE44 } & \multicolumn{2}{c}{ AE44-T5 } \\
\cline { 2 - 10 } & $\boldsymbol{\Theta}$ & $\boldsymbol{\sigma}_{\mathbf{y}, \text { III }}$ & $\boldsymbol{\Theta}$ & $\boldsymbol{\sigma}_{\mathbf{y}, \text { III }}$ & $\boldsymbol{\Theta}$ & $\boldsymbol{\sigma}_{\mathbf{y}, \text { III }}$ & $\boldsymbol{\Theta}$ & $\boldsymbol{\sigma}_{\mathbf{y}, \text { III }}$ & $\boldsymbol{\Theta}$ & $\boldsymbol{\sigma}_{\mathbf{y}, \text { III }}$ \\
\hline $\mathbf{1 0}^{-\mathbf{6}}$ & $1299 \pm 27$ & $127 \pm 0.4$ & $1334 \pm 33$ & $145 \pm 1.1$ & $2264 \pm 84$ & $180 \pm 3.4$ & $1187 \pm 4.7$ & $142 \pm 1.4$ & $977 \pm 11$ & $169 \pm 4.0$ \\
$\mathbf{1 0}^{-5}$ & - & - & - & - & - & - & $1400 \pm 19$ & $145 \pm 1.0$ & $1203 \pm 2.3$ & $178 \pm 0.6$ \\
$\mathbf{1 0}^{-4}$ & $1437 \pm 16$ & $126 \pm 0.6$ & $1479 \pm 9.6$ & $148 \pm 1.9$ & $2271 \pm 13$ & $185 \pm 1.9$ & $1606 \pm 16$ & $151 \pm 1.3$ & $1435 \pm 8.1$ & $188 \pm 1.3$ \\
$\mathbf{1 0}^{-3}$ & - & - & - & - & - & - & $1645 \pm 5.7$ & $156 \pm 1.3$ & $1555 \pm 2.6$ & $194 \pm 0.9$ \\
$\mathbf{1 0}^{-2}$ & $1512 \pm 18$ & $131 \pm 2.2$ & $1509 \pm 0.1$ & $147 \pm 0.6$ & $2381 \pm 1.9$ & $188 \pm 0.2$ & $1693 \pm 31$ & $162 \pm 0.5$ & $1601 \pm 17$ & $201 \pm 0.2$ \\
$\mathbf{1 0}^{-1}$ & - & - & $1512 \pm 32$ & $150 \pm 1.2$ & $2252 \pm 48$ & $190 \pm 0.8$ & $1776 \pm 18$ & $165 \pm 1.4$ & $1728 \pm 9.1$ & $206 \pm 1.9$ \\
\hline
\end{tabular}

Table 2. Parameters in Stage III: $\Theta(\mathrm{MPa})$ and $\sigma_{\mathrm{y}, \mathrm{III}}(\mathrm{MPa})$ of best fit of Eq. (5) measured from experimental flow curves.

Fig. 7 compares the measured $\Theta$ from Eq. (5) with the modelled $\Theta$ predicted from Eq. (9).

367 T5 are also shown and it is clear that they fall within the expected range of 1000-2000 MPa 368 [17] for AM40, AM60, AE44 and AE44-T5. AZ91, however, has a higher $\Theta_{\mathrm{h}}$ of $2300 \mathrm{MPa}$. 369 Overall, Eq. (9) describes the behavior of $\Theta$ well. 


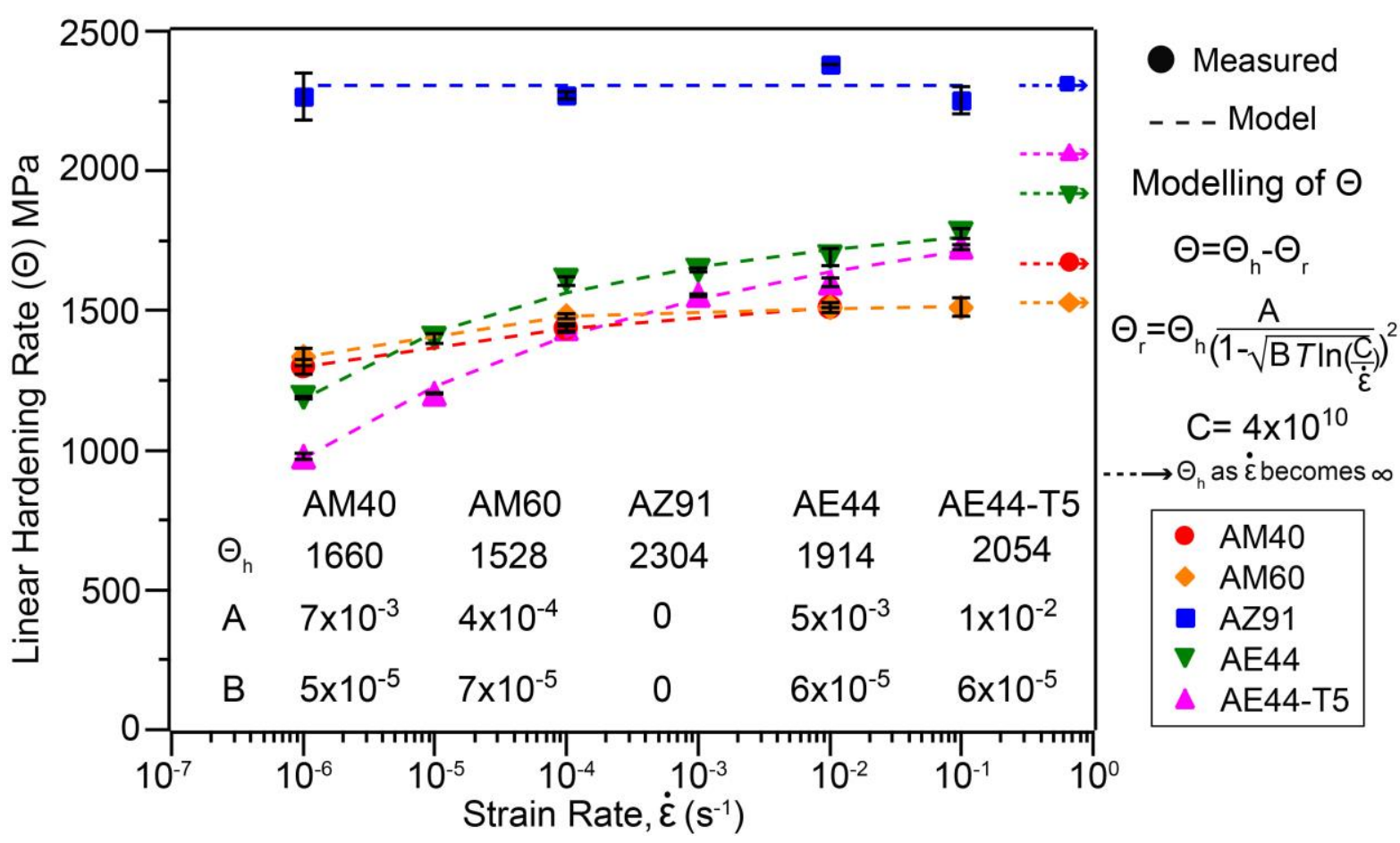

Fig. 7. The strain hardening rate, $\Theta$ in Stage III for the studied alloys at different strain rates. The solid filled symbol and dashed line indicate the measured $\Theta$ using Eq. (5) and the modelled $\Theta$ with Eq. (9), respectively. The values of $\Theta_{h}$ and constants $A, B$, and $C$ for each alloy are shown.

It is interesting to see that the optimum value of constant $\mathrm{C}$ which provides the lowest scatter is $\sim 10^{10} \mathrm{~s}^{-1}$ for present die-cast alloys. For FCC metal, this value is $\sim 10^{7} \mathrm{~s}^{-1}$ determined by trial and error in [13].

To model $\sigma_{\mathrm{y}, \mathrm{III}}$, the temperature dependent exponent, $\mathrm{n}$ in Eq. (13) is first calculated. By using a Boltzmann constant, $\mathrm{k}$ of $1.38 \times 10^{-23} \mathrm{~m}^{2} \mathrm{~kg} \mathrm{~s}^{-2} \mathrm{~K}^{-1}$, shear modulus, $\mu$ of $\mathrm{Mg}$ (17 GPa), the magnitude of the Burgers vector, $b$ of magnesium $(0.32 \mathrm{~nm})$ [70] at room temperature $T=$ $295.15 \mathrm{~K}$, the temperature dependent exponent, $\mathrm{n}$ in Eq. (13) is calculated to be 0.0073 . The $\mathrm{n}$ value correlates well with the literature data where $n$ is reported to be $0-0.03$ [13] within a strain-rate range of $10^{-4}-10^{0} \mathrm{~s}^{-1}$, at room temperature.

Applying $\mathrm{n}$ of 0.0073 and $\dot{\varepsilon}_{0}$ of $4 \times 10^{10} \mathrm{~s}^{-1}$ (constant $\mathrm{C}$ in Fig. 7), $\sigma_{\mathrm{y}, \mathrm{III}}$ is modelled and compared with measured $\sigma_{y, I I I}$ from experimental flow curves as shown in Fig. 8. There is a good agreement between the measured $\sigma_{\mathrm{y}, \mathrm{III}}$ and modelled $\sigma_{\mathrm{y}, \mathrm{III}}$, confirming the good fit of values of $\dot{\varepsilon}_{0}$ and n determined. 


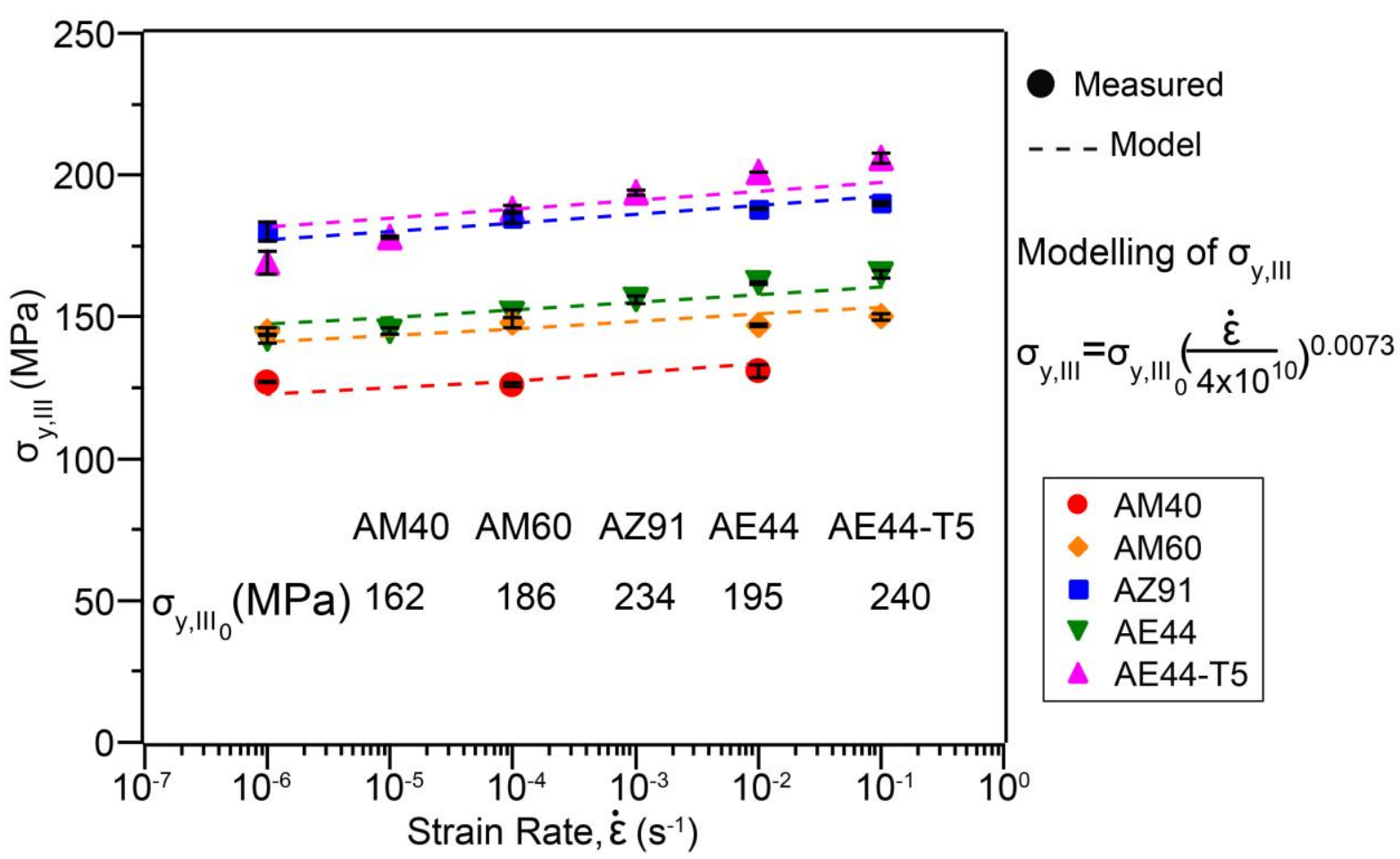

Fig. 8. The $\left\langle\mathrm{a}>\right.$ prismatic yield stress, $\sigma_{\mathrm{y}, \mathrm{III}}$ of present alloys at different strain rates. The solid filled symbol and dashed line indicate $\sigma_{\mathrm{y}, \mathrm{III}}$ measured from experimental flow curves using Eq. (5) and the modelled $\sigma_{\mathrm{y}, \mathrm{III}}$ with Eq. (13), respectively. The value of $\sigma_{\mathrm{y}, \mathrm{III}}$ (MPa) for each alloy is shown.

\subsubsection{Stage IV: $\langle c+a\rangle$ Pyramidal}

As deformation continues, the internal stresses are high enough to activate additional nonbasal slip systems, which in $\mathrm{Mg}$ and alloys is $\langle\mathrm{c}+\mathrm{a}\rangle$ pyramidal slip [32]. Activation of an additional slip system allows dislocations piled-up at obstacles due to cross slip in the previous stage to escape, reducing the internal-strain field. This process is called dynamic recovery, and strain hardening decreases until fracture occurs [15]. This stage is also more sensitive to strain rate and temperature than Stage III ( $<$ a $>$ prismatic slip-dominated stage), and may limit the extent of Stage III deformation, especially at low strain rates or high temperatures when $\langle\mathrm{c}+\mathrm{a}\rangle$ pyramidal slip activates early [30]. The stress-strain curve in this stage has been reported to follow Hollomon's equation: a power-law relationship between stress and amount of $\langle\mathrm{c}+\mathrm{a}\rangle$ pyramidal strain $[36,71,72]$ :

$$
\sigma=K_{I V} \varepsilon_{I V}{ }^{n_{I V}}
$$

where $\varepsilon_{\text {IV }}$ is the Stage IV strain or $\left\langle\mathrm{c}+\mathrm{a}>\right.$ pyramidal strain, $\mathrm{K}_{\mathrm{IV}}$ is the strength coefficient and $\mathrm{n}_{\mathrm{IV}}$ is the strain hardening exponent in Stage IV.

Fig. 9 compares the experimental (solid) and the best fitted (dashed) stress-strain curve of Stage IV; the parameters $\mathrm{K}_{\mathrm{IV}}$ and $\mathrm{n}_{\mathrm{IV}}$ from two sets of data are summarized in Table 3 . It is clear that Eq. (14) can describe this part of the flow curve reasonably well. It is also interesting to see that $\langle\mathrm{c}+\mathrm{a}\rangle$ pyramidal slip starts to dominate above an applied stress of $\sim 200 \mathrm{MPa}$ for 
both AZ91 and AE44; slightly higher with increasing strain rates. Below $200 \mathrm{MPa},\langle\mathrm{c}+\mathrm{a}>$ pyramidal strain, $\varepsilon_{\mathrm{IV}}$ is insignificant. It is also observed that AZ91 has considerably less total $<\mathrm{c}+\mathrm{a}>$ pyramidal strain as compared to AE44 (the scale on the $\mathrm{x}$-axis of AZ91 is smaller). This is because AZ91 fractures earlier before $<c+a>$ pyramidal strain becomes too extensive.

421

(a)

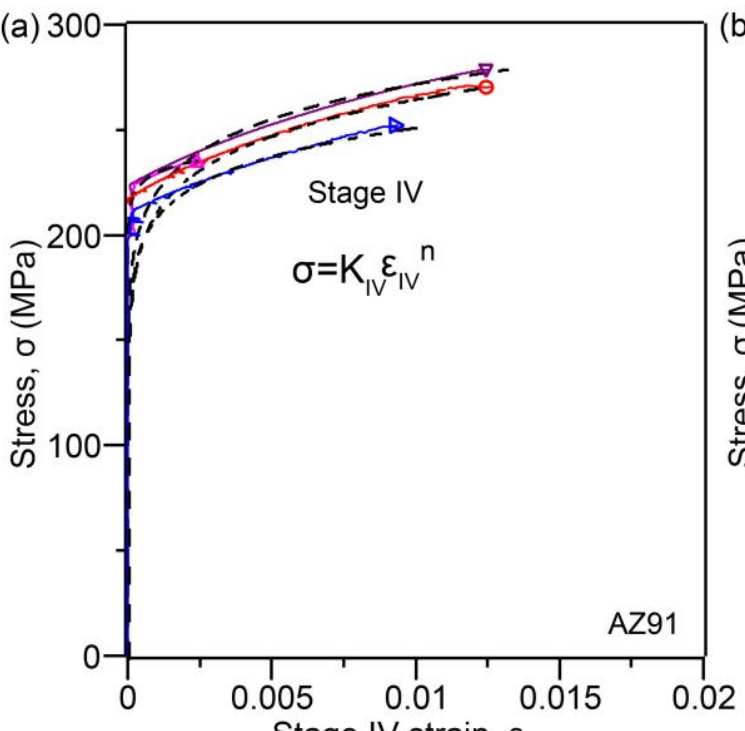

Stage IV strain, $\varepsilon_{\mathrm{IV}}$

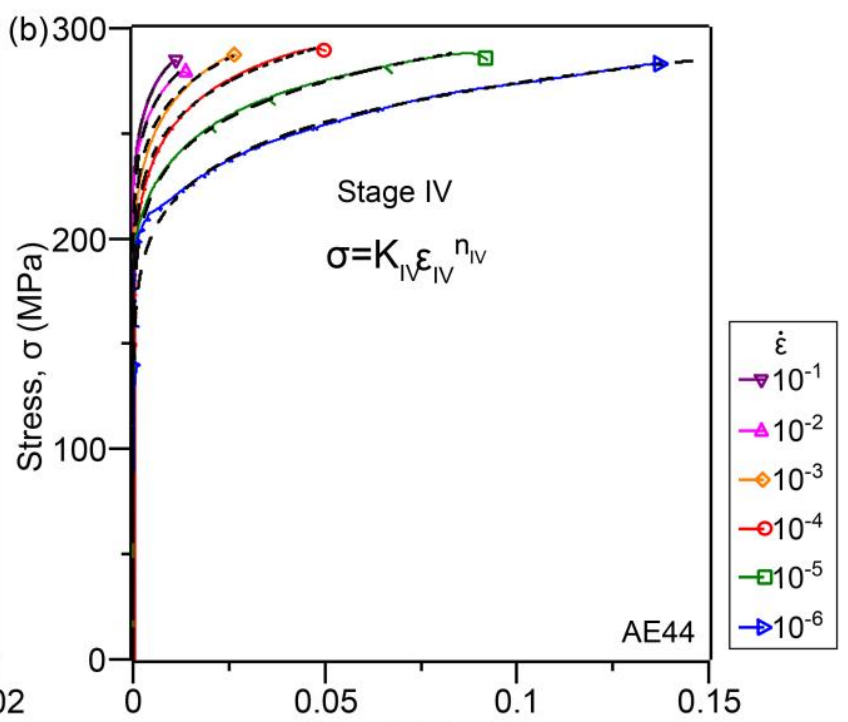

Stage IV strain, $\varepsilon_{\mathrm{IV}}$
422

427

Fig. 9. The experimental (solid) and the best fitted (dashed) stress-strain curve of Stage IV for (a) AZ91 and (b) AE44. Note the different scales on the x-axis between the two alloys.

Table 3. Parameters in Stage IV: $\mathrm{K}_{\mathrm{IV}}$ (MPa) and $\mathrm{n}_{\mathrm{IV}}$ of best fit of Eq. (14).

\begin{tabular}{|c|c|c|c|c|c|c|c|c|c|c|}
\hline \multirow{2}{*}{$\dot{\boldsymbol{\varepsilon}}$} & \multicolumn{2}{|c|}{ AM40 } & \multicolumn{2}{|c|}{ AM60 } & \multicolumn{2}{|c|}{ AZ91 } & \multicolumn{2}{|c|}{ AE44 } & \multicolumn{2}{|c|}{ AE44-T5 } \\
\hline & $\mathbf{K}_{\text {IV }}$ & $\operatorname{nIV}\left(10^{-3}\right)$ & $K_{\text {IV }}$ & $\operatorname{niv}_{I V}\left(10^{-3}\right)$ & $\mathbf{K}_{\text {IV }}$ & $\operatorname{nIV}\left(10^{-3}\right)$ & $\mathbf{K}_{\text {IV }}$ & $\operatorname{nIV}\left(10^{-3}\right)$ & $K_{\text {IV }}$ & $\operatorname{nIV}\left(10^{-3}\right)$ \\
\hline $10^{-6}$ & $373 \pm 1.6$ & $106 \pm 0.8$ & $396 \pm 1.4$ & $97 \pm 2.7$ & $363 \pm 0.6$ & $76 \pm 3.3$ & $347 \pm 1.3$ & $101 \pm 0.8$ & $334 \pm 4.0$ & $73 \pm 0.4$ \\
\hline $10^{-5}$ & - & - & - & - & - & - & $366 \pm 2.4$ & $92 \pm 1.6$ & $361 \pm 0.5$ & $68 \pm 0.2$ \\
\hline $10^{-4}$ & $376 \pm 3.6$ & $96 \pm 2.3$ & $399 \pm 3.2$ & $85 \pm 0.5$ & $415 \pm 0.0$ & $97 \pm 0.0$ & $377 \pm 1.0$ & $85 \pm 1.1$ & $385 \pm 1.2$ & $63 \pm 0.2$ \\
\hline $10^{-3}$ & - & - & - & - & - & - & $389 \pm 5.1$ & $81 \pm 1.2$ & $394 \pm 0.7$ & $59 \pm 0.0$ \\
\hline $10^{-2}$ & $379 \pm 5.6$ & $95 \pm 0.8$ & $382 \pm 0.9$ & $79 \pm 0.9$ & $410 \pm 0.0$ & $93 \pm 0.0$ & $384 \pm 2.3$ & $72 \pm 1.6$ & $399 \pm 2.6$ & $55 \pm 0.5$ \\
\hline $10^{-1}$ & - & - & $378 \pm 1.1$ & $74 \pm 0.4$ & $422 \pm 8.3$ & $94 \pm 3.2$ & $389 \pm 1.7$ & $68 \pm 0.0$ & $402 \pm 0.0$ & $51 \pm 0.6$ \\
\hline
\end{tabular}

428

The parameters $\mathrm{K}_{\mathrm{IV}}$ and $\mathrm{n}_{\mathrm{IV}}$ from Eq. (14) can be further defined in the form of Ludwik's empirical equation [73] as shown in Eq. (15) or Hollomon's equation [71] in Eq. (16):

$$
\mathrm{K}_{\mathrm{IV}} \text { or } \mathrm{n}_{\mathrm{IV}}=\mathrm{a}\left[1-\mathrm{b} \dot{\varepsilon}^{\mathrm{c}}\right]
$$

where $\mathrm{a}, \mathrm{b}, \mathrm{c}, \mathrm{d}$ and $\mathrm{f}$ are constants. To determine which model is more accurate for the present die-cast alloys, both Ludwik's and Hollomon's constitutive models are compared with 
the measured $K_{I V}$ and $n_{I V}$ obtained from best fit of Eq. (14) (Table 3), as shown in Fig. 10 for AE44.

(a) 40

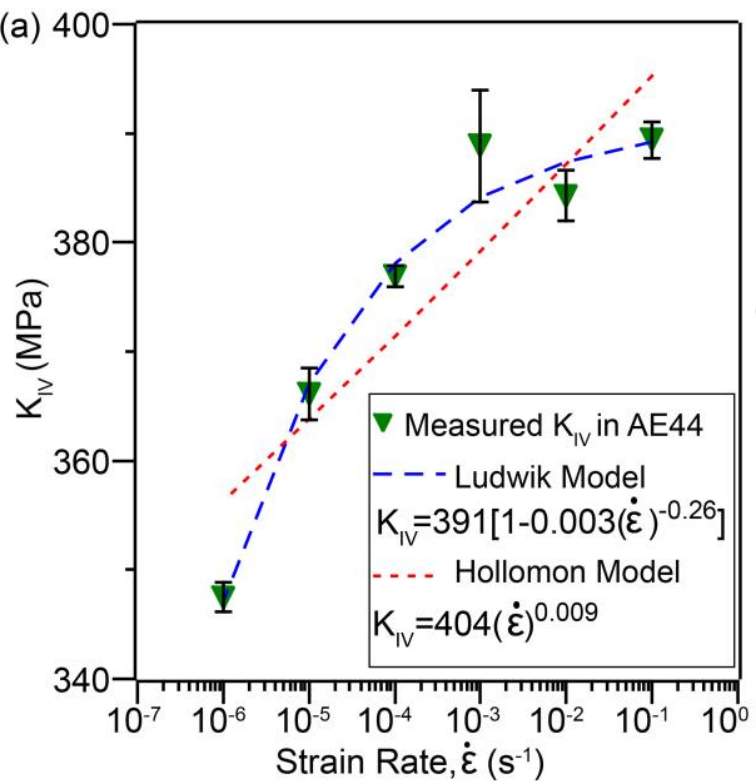

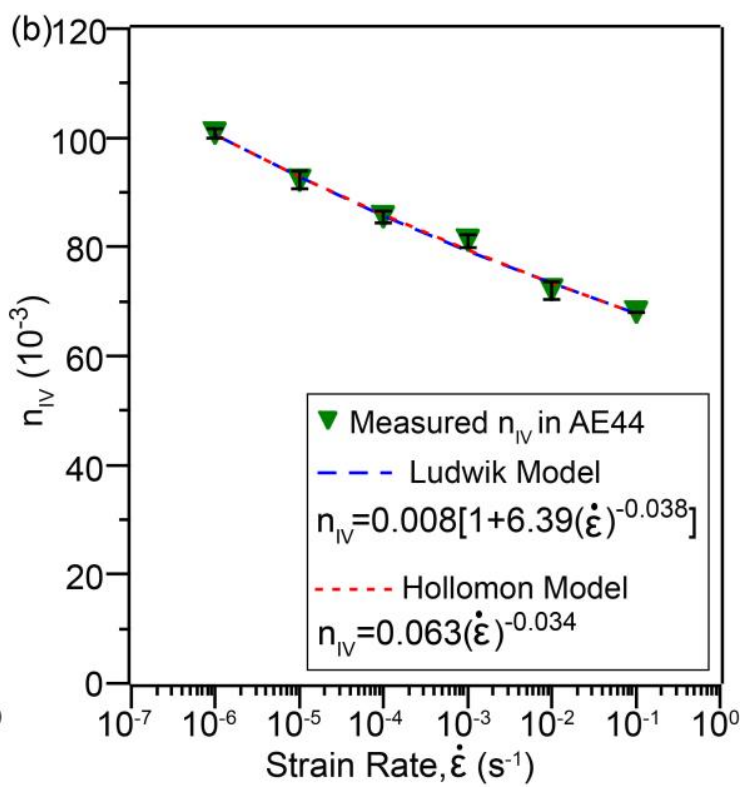

Fig. 10. Comparison of Ludwik's and Hollomon's models with $\mathrm{K}_{\mathrm{IV}}$ and $\mathrm{n}_{\mathrm{IV}}$ of best fit of Eq. (14).

Ludwik's model provides a slightly better correlation to the measured $\mathrm{K}_{\mathrm{IV}}$ compared to Hollomon's model. For determining n acceptable. Using Ludwik's model for $\mathrm{K}_{\mathrm{IV}}$ and Hollomon's model for $\mathrm{n}_{\mathrm{IV}}$, the values of constants are summarized in Table 4 for present die-cast alloys. Given that both models provide good descriptions of the data, Hollomon's model was selected to determine $\mathrm{n}_{\mathrm{IV}}$ due to its relative simplicity.

Table 4. The values of constants $a, b, c, d$ and f from Eqs. (15) and (16).

\begin{tabular}{cccccc}
\hline \multirow{2}{*}{ Alloy } & \multicolumn{3}{c}{$\mathbf{K}_{\mathbf{I V}=\mathbf{a}\left[\mathbf{1 - b} \dot{\boldsymbol{\varepsilon}}^{\mathbf{c}}\right]}$} & \multicolumn{2}{c}{$\mathbf{n}_{\mathbf{I V}=\mathbf{d} \dot{\boldsymbol{\varepsilon}}^{\mathbf{f}}}$} \\
\cline { 2 - 6 } & $\mathbf{a}$ & $\mathbf{b}$ & $\mathbf{c}$ & $\mathbf{d}$ & $\mathbf{f}$ \\
\hline AM40 & 385 & 0.011 & -0.069 & 0.088 & -0.0128 \\
AM60 & 400 & 0.095 & 0.212 & 0.070 & -0.0230 \\
AZ91 & 110 & -2.926 & 0.014 & 0.099 & 0.0163 \\
AE44 & 391 & 0.003 & -0.261 & 0.063 & -0.0343 \\
AE44-T5 & 408 & 0.007 & -0.232 & 0.047 & -0.0316 \\
\hline
\end{tabular}

\subsubsection{Complete Stress-Strain Curve}

The contribution to the strain from the four stages of deformation identified has been determined using Eq. (1); the complete stress-strain curve can now be modelled. The contributions of each of the deformation regimes are illustrated in Fig. 11. One of the slightly 
confusing aspects of this analysis is that the independent variable is stress and strain is the independent variable, as deformation is dependent on the materials response to the stress applied, despite the typical representation of the stress-strain curve. To understand the graphical representation (Fig. 11(a)), the applied stress needs to be considered. At a particular value of applied stress, there is a contribution from previous stages of strain. At low stresses, only Stage I (elastic strain) contributes. As the stress increases to Stage II, <a> basal slip and twinning occur but this reaches a maximum when Stage III ( $<a>$ prismatic) slip is introduced and finally Stage IV $(<c+a>$ pyramidal) slip occurs. The contribution of each of the stages of deformation is shown in Fig. 11(b) and shows that it is once Stage III (attributed to $<\mathrm{a}>$ prismatic slip) occurs that extensive plasticity is observed in AE44 (and the other alloys studied here).

$$
\text { (a) } 300
$$

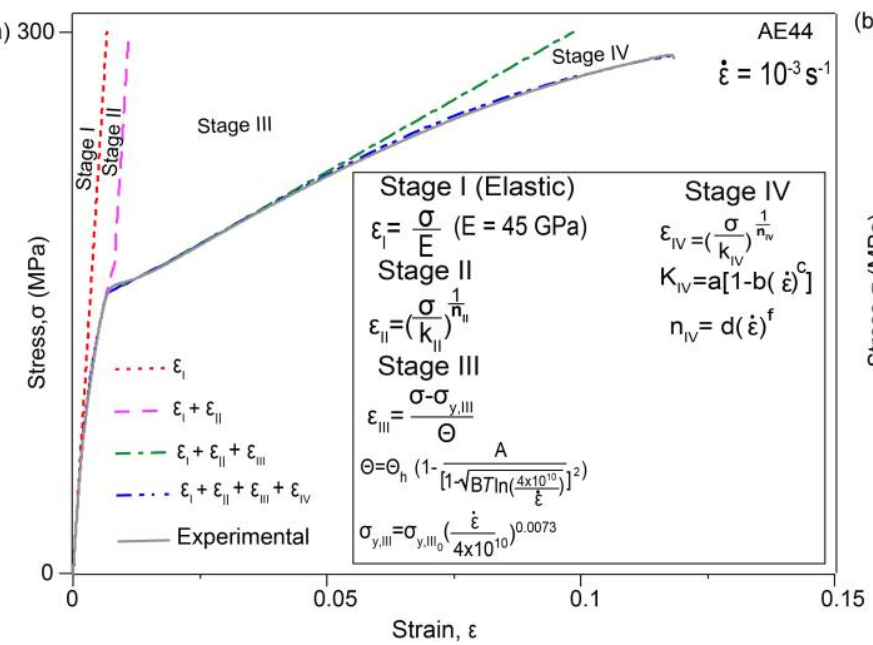

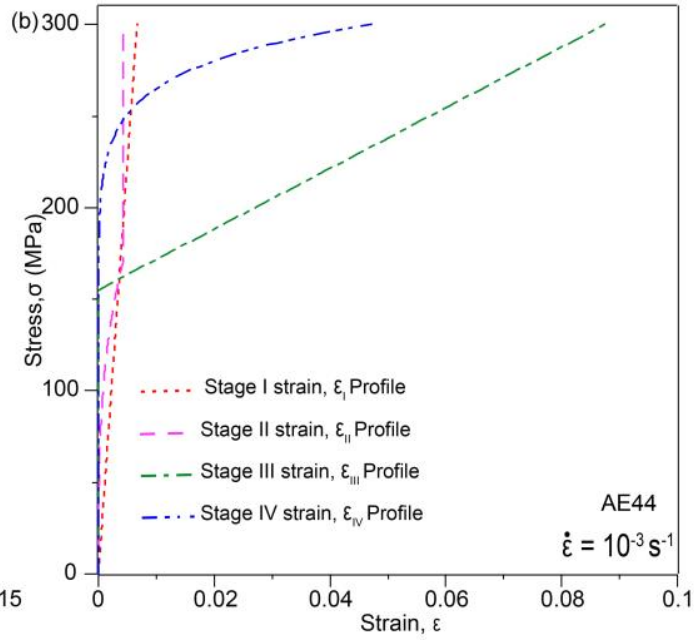

Fig. 11. (a) An example of the experimental (solid) and modelled (dashed) stress-strain curves showing the contributions of strain for each of the stages of deformation, with each of the stages adding onto the previous stages of strain as per Eq. (1). (b) The individual contributions of strain for each of the stages of deformation for AE44 as shown in (a).

A generic mathematical description of the stress-strain data observed in Fig. 11 can be described by combining Eqs. (2), (4), (5) and (14) and the total strain, $\varepsilon_{\mathrm{t}}$ can be calculated using Eqs. (17a) and (17b) depending on the conditions stated:

when $\sigma \leq \sigma_{\mathrm{y}, \mathrm{III}}$ :

$$
\varepsilon_{\mathrm{t}}=\frac{\sigma}{\mathrm{E}}+\frac{\sigma}{\mathrm{K}_{\mathrm{II}}} \frac{1}{\mathrm{n}_{\mathrm{II}}}
$$

$$
\text { when } \sigma>\sigma_{\mathrm{y}, \mathrm{III}}: \quad \varepsilon_{\mathrm{t}}=\frac{\sigma}{\mathrm{E}}+\frac{\sigma_{\mathrm{II}}}{\mathrm{K}_{\mathrm{II}}} \frac{1}{\mathrm{n}_{\mathrm{II}}}+\frac{\sigma-\sigma_{\mathrm{y}, \mathrm{III}}}{\Theta}+\frac{\sigma}{\mathrm{K}_{\mathrm{IV}}} \frac{1}{\mathrm{n}_{\mathrm{IV}}}
$$

In Eq. (17b), there is a condition for Stage II strain (second term): 


$$
\sigma_{\mathrm{II}}=\left\{\begin{array}{cl}
\sigma_{0.01, \mathrm{III}}, & \text { when } \sigma \geq \sigma_{0.01, \mathrm{III}} \text { for AM40, AM60, AE44 } \\
\sigma_{0.015, \mathrm{III}}, & \text { when } \sigma \geq \sigma_{0.015, \mathrm{III}} \text { for AZ91 } \\
\sigma, & \text { otherwise }
\end{array}\right\}
$$

488 503

To verify the validity of this approach, stress is used as the independent variable in Eq. (17b) to model the complete stress-strain curve for all the studied alloys as shown in Fig. 12. Stage II strain (second term) remains constant above the stress at which Stage III strain reaches 0.01 for AM40, AM60, AE44, AE44-T5 and 0.015 for AZ91. $\sigma_{0.01, \text { III }}$ and $\sigma_{0.015, \text { III }}$ denote the stresses when Stage III strain, $\varepsilon_{\text {III }}$, reaches 0.01 and 0.015 , respectively as shown in Fig. 4.

It is clear that there is a good agreement between experimental (colored) and modelled stress-strain curves (black dashed) for all the alloys. Non-basal slip (prismatic and pyramidal) is difficult to activate at room temperature as their critical resolved shear stress (CRSS) is several orders of magnitude greater than that of basal slip [74]. At room temperature, the CRSS of prismatic slip in $\mathrm{Mg}$ polycrystal is $\sim 110 \mathrm{MPa}$ [75], whereas the CRSS of basal slip and extension twinning are $\sim 10 \mathrm{MPa}$ [20] and $30 \mathrm{MPa}$ [76], respectively for $\mathrm{Mg} \mathrm{AZ31}$. The onset of basal slip and twinning is the factor for onset of Stage II and onset of prismatic slip applies to Stage III. Die-cast alloys are randomly textured, and no particular deformation mode is favored, therefore each deformation mode will be activated upon reaching their CRSS.
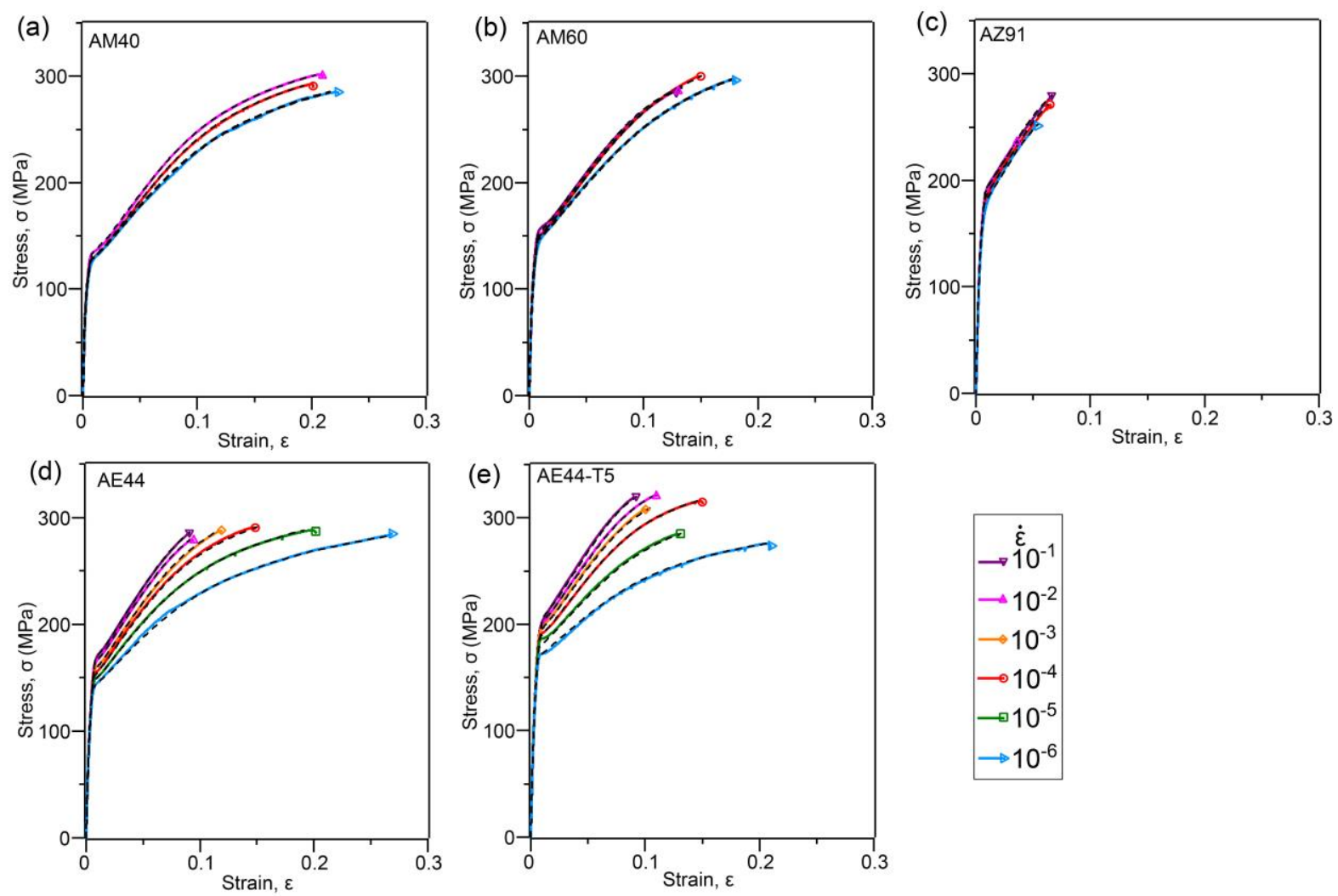

Fig. 12. Comparison of experimental (coloured) and modelled (black dashed) stress-strain curves of (a) AM40, (b) AM60, (c) AZ91, (d) AE44, and (e) AE44-T5 at wide strain-rate range $10^{-6}-10^{-1} \mathrm{~s}^{-1}$. 


\section{Discussion}

\subsection{Strain-rate Sensitivity at Different Stages}

The results show that some stages of the stress-strain curve, such as Stages III and IV are more strain-rate sensitive. The change in strain-rate sensitivity is also greater in alloys with lower Al contents in solid solution, for example AE44. The discussion will now consider how the underlying deformation mechanisms affect the deformation behavior in these stages.

Both Stages I and II are strain-rate insensitive. In Stage II, this is supported by the large statistical deviation of $\mathrm{K}_{\mathrm{II}}$ in Table 1, probably resulting from experimental variation for a given strain rate. In this study, the dominant deformation mechanisms in Stage II are attributed to $<a>$ basal slip and twinning. One piece of evidence to support this is that the CRSS of <a> basal slip and twinning are known to be strain-rate independent [35, 59-62], leading to the strain-rate insensitivity in this stage. While $\mathrm{K}_{\mathrm{II}}$ is strain-rate independent, it is alloy dependent. $\mathrm{K}_{\mathrm{II}}$ is connected to the interaction of dislocations with obstacles and is expected to increase with increasing solute content [77]. In Table 1, it is clear that among the $\mathrm{Mg}$-Al based alloys AM40, AM60 and AZ91 without RE addition, AZ91 consistently shows the highest $\mathrm{K}_{\text {II }}$ due to its high Al solute concentrations. For alloys with RE addition, the $\mathrm{K}_{\mathrm{II}}$ values of as-cast AE44 are higher than AE44-T5 for a given strain rate. AE44-T5 has lower Al solute in solution but it also contains nanoscale Al-Mn particles as a result of precipitation [51]. It is not known why AE44-T5 with precipitates has a lower value of $\mathrm{K}_{\mathrm{II}}$ compared to AE44. Further investigation is required. The $\mathrm{n}_{\text {II }}$ values which measure the ability of a metal to strain harden are also quite consistent between strain rates and alloys, and can range from 0.19-0.37.

Both Stages III and IV are more strain-rate sensitive in AE44 and AE44-T5 as compared to AM40, AM60 and AZ91. The dominant deformation mechanism in Stages III and IV are ascribed to $\langle\mathrm{a}\rangle$ prismatic slip and $\langle\mathrm{c}+\mathrm{a}\rangle$ pyramidal slip, respectively. The CRSS of $\langle\mathrm{a}\rangle$ prismatic and $\langle\mathrm{c}+\mathrm{a}>$ pyramidal slip are known to be strain-rate sensitive $[59,61,78]$, and this further supports the notion that it is the presence of these deformation mechanisms that leads to the strain-rate sensitivity in AE44 and AE44-T5. In contrast, the AM and AZ alloys have higher $\mathrm{Al}$ solute concentration and $\mathrm{Al}$ solute has been reported to impede slip, lowering the strain-rate sensitivity in Stages III and IV due to the dynamic strain aging effect [4].

Note that the notion of different deformation mechanisms dominating in the four deformation stages was generated from the literature which shows that the deformation first occurred by $<a>$ basal slip and twinning followed by $<a>$ prismatic and $\langle\mathrm{c}+\mathrm{a}\rangle$ pyramidal slip in $\mathrm{Mg}$ and alloys [14, 15, 20, 79].

\subsection{The Delayed Saturation of Anelasticity in AZ91}

Both AE44-T5 and AZ91 are high-strength alloys, but anelasticity in Stage II in AZ91 saturates at a higher $\varepsilon_{\text {III }}(0.0015)$ as shown in Fig. 4. As previously reported [5], an effect of $\mathrm{Al}$ at high concentrations such as $9 \mathrm{wt} . \%$ in AZ91 is to delay the onset of $\langle\mathrm{a}\rangle$ prismatic slip (Stage III). A delay in the onset of Stage III will extend Stage II and more twinning is necessary to accommodate the deformation, such that the anelasticity saturates at higher $\varepsilon_{\text {III }}$.

The intergranular percolating network of eutectic $\mathrm{Mg}_{17} \mathrm{Al}_{12}$ may also have a measurable effect on the alloy's Stage II deformation. In a highly concentrated alloy such as AZ91, the percolating intermetallic is not only abundant, but also fully interconnected, and this further 
increases the strain hardening effect, but reduces the ductility due to the increased tendency of crack propagation through the interconnected micro-trusses in AZ91 [80, 81]. It is likely that the micro-trusses in AZ91 begin to fail at $\varepsilon_{\text {III }}$ of approximately 0.01 as suggested by [80], which contributes an additional strain of 0.005 , making up the strain of 0.015 when anelasticity saturates. In contrast, more dilute alloys such as AM40 and AM60 are less affected by the micro-truss failure in Stage II due to a reduced interconnection of the percolating intermetallic network [82]. Ternary Mg-Al-RE alloy AE44 consists of a different type of Al-RE intermetallics and further investigation is required to understand the micro-trusses' strain to failure in this alloy.

\subsection{Athermal and Thermal Components in Stage III}

The strain hardening rate, $\Theta$, in Stage III is made up of two components: athermal component $\Theta_{\mathrm{h}}$ and thermal component $\Theta_{\mathrm{r}}$. In the event at the limit of the highest strain rate or lowest temperature, when $\Theta_{\mathrm{r}}$ (softening effect) becomes negligible, $\Theta=\Theta_{\mathrm{h}}$. It has previously been assumed that $\Theta_{\mathrm{r}}$ is negligible in Stage III $[14,15,17]$ and it becomes significant only in Stage IV when dynamic recovery occurs. However, it is clear now from Fig. 7 that there is some contribution of $\Theta_{\mathrm{r}}$, especially for AM40, AM60, AE44 and AE44-T5. The effect of $\Theta_{\mathrm{r}}$ is less in AZ91 in Stage III, presumably due to its high Al solute concentration and fully interconnected percolating intermetallic network which makes dislocation annihilation difficult. This also explains the high $\Theta_{\mathrm{h}}$ in AZ91.

\subsection{Applicability of the Current Analysis Approach}

It should be noted that the current analysis approach is conducted on the die-cast $\mathrm{Mg}$ alloys. Die-cast $\mathrm{Mg}$ alloys are randomly textured and no particular deformation mode is favoured, therefore each deformation mode will be activated upon reaching their CRSS. It is generally accepted that at room temperature and quasi-static strain rates, CRSS $_{\text {basal }}<$ $\mathrm{CRSS}_{\text {extension twinning }}<\mathrm{CRSS}_{\text {prismatic }}<\mathrm{CRSS}_{\text {pyramidal }}[20,40,76,83]$. Non-basal slip (prismatic and pyramidal) are difficult to activate at room temperature as their CRSS at room temperature is several orders of magnitude greater than that of basal slip [74, 75]. As these four stages are mutually exclusive in randomly textured die-cast alloys, the stress-strain curve can easily be decomposed into four distinct stages and modelling of the complete stress-strain curve can be achieved by addition of these stages. Wrought alloys are textured and deformation modes are dependent on the loading direction, and thus, the dominant deformation modes and crystal plasticity approaches are often required to model the stress-strain behavior [36, 76, 84, 85].

It is also worth noting that the current analysis is limited to the quasi-static strain rate regime. At dynamic strain rates above $10^{3} \mathrm{~s}^{-1}$, other modes of twinning have been reported to contribute more extensively to deformation [86-89]. Extension twins $\{10 \overline{1} 2\}$, contraction twins $\{10 \overline{1} 1\}$ and double twins $\{10 \overline{1} 1\}-\{10 \overline{1} 2\}$ have been observed in cast AE42 and AE44 alloys [86], in cast AZ alloys [87] and multiple $\{10 \overline{1} 2\}$ twin variants were activated in hot-rolled AZ31 alloy [88] during dynamic tests at and above $10^{3} \mathrm{~s}^{-1}$. These different types of twinning systems and $\{10 \overline{1} 2\}$ twin variants activated at dynamic strain rates may occur simultaneously and inevitably interact with each other. This can lead to the high strain hardening rate as observed in the sigmoidal shape of stress-strain curve associated with twinning-dominated 
deformation. These different types of twins have not been observed to partially revert (untwin) like the extension twins upon unloading, and this makes the quantification of their individual contribution to the overall stress-strain curve difficult using the approach used here. The increase in twinning activity also changes the texture of cast $\mathrm{AE}$ and $\mathrm{AZ}$ alloys from nearrandom texture to a strong basal texture $[86,87]$.

\section{Conclusions}

The tensile deformation behavior of commercial high-pressure die-cast magnesiumaluminium based alloys has been analyzed and modelled. The following conclusions are drawn from this study:

1) The stress-strain curve can be separated into four stages. Stage I is the elastic region. Stage II is $\langle a>$ basal slip and twinning dominated, while Stages III and IV are <a> prismatic slip and $\langle\mathrm{c}+\mathrm{a}\rangle$ pyramidal slip dominated, respectively.

2) The four deformation stages of stress-strain curve are modelled by mathematical equations. Stages I and III exhibit a linear strain hardening region and can be described by a simple linear equation while Stages II and IV exhibit a power relationship of stress and strain and are described by Hollomon's equation. These equations are combined to model the entire stress-strain curve. The proposed model provides a good fit to the experimental stress-strain curve.

3) Stages I and II are observed to be strain-rate insensitive while Stages III and IV exhibit high strain-rate sensitivity in alloys with lower aluminium contents in solid solution. This is attributed to the strain-rate sensitivity of the different deformation mechanisms. The reduced strain-rate sensitivity in Stages III and IV in alloys with higher aluminium contents in solid solution is attributed to the previously reported dynamic strain aging effect.

\section{Acknowledgements}

This work was supported by the Australian Research Council [Grant number LP130100828]. The authors would like thank Professor Matthew Barnett from Deakin University for their very helpful comments on the manuscript. 
[1] P. Bakke, K. Pettersen, H. Westengen: J. Miner. Metals Mater. Soc., 2003, vol. 55, pp. 46-51.

[2] M. Avedesian, H. Baker: Magnesium and magnesium Alloys-ASM Specialty Handbook, vol. 52, ASM International. Ohio: The Materials Information Society, 1999.

[3] B.L. Mordike, T. Ebert: Mater. Sci. Eng. A, 2001, vol. 302, pp. 37-45.

[4] H.Q.Ang, S.M.Zhu, T.B.Abbott, D.Qiu, M.A.Easton: Mater. Sci. Eng. A, 2017, vol. 699, pp. 239-246.

[5] H.Q. Ang, T.B. Abbott, S.M. Zhu, M.A. Easton: Mater. Sci. Eng. A, 2017, vol. 707, pp. 101-109.

[6] H.Q. Ang: Mechanical Properties and Deformation Behaviour of High-Pressure DieCast Magnesium-Aluminium Based Alloys [dissertation], Royal Melbourne Institute of Technology, Melbourne, 2017.

[7] H.Q. Ang, T.B. Abbott, S.M. Zhu, C.F. Gu, M.A. Easton: Mater. Des., 2016, vol. 112, pp. 402-409.

[8] C.H. Cáceres, T. Sumitomo, M. Veidt: Acta Mater., 2003, vol. 51, pp. 6211-6218.

[9] G.E. Mann, T. Sumitomo, C.H. Cáceres, J.R. Griffiths: Mater. Sci. Eng. A, 2007, vol. 456, pp. 138-146.

[10] D. Nagarajan, X. Ren, C.H. Cáceres: Mater. Sci. Eng. A., 2017, vol. 696, pp. 387-392.

[11] D. Nagarajan: Mater. Sci. Eng. A., 2017, vol. 695, pp. 14-19.

[12] A.D. Rollett, U.F. Kocks: A review of the stages of work hardening, Proceedings of Dislocations-93 Conference, 1993 Apr 1-9, Aussois, France, Trans Tech Publ, 1993, pp. $1-18$.

[13] U.F. Kocks, H. Mecking: Prog. Mater. Sci., 2003, vol. 48, pp. 171-273.

[14] K.V. Yang, C.H. Cáceres, A.V. Nagasekhar, M.A. Easton: Model. Simul. Mater. Sci. Eng., 2012, vol. 20, pp. 024010.

[15] K.V. Yang, C.H. Cáceres, C.N. Tomé: in Magnesium Technology 2012, Mathaudhu SN, Sillekens WH, Neelameggham NR, Hort N, eds., The Minerals, Metals \& Materials Society, 2012 Mar 11-15, Orlando, Florida, 2012, pp. 127-131.

[16] C.H. Cáceres, P. Lukáč: Philos. Mag., 2008, vol. 88, pp. 977-989.

[17] C.H Cáceres, A. Blake: Mater. Sci. Eng. A, 2007, vol. 462, pp. 193-196.

[18] Z.J. Lu, P. Blackmore: SAE Int. J. Mater. Manuf., 2014, vol. 7, pp. 446-453.

[19] A. Akhtar, E. Teghtsoonian: Mater. Trans., 1968, vol. 9, pp. 692-697.

[20] S.R. Agnew, C.N. Tomé, D.W. Brown, T.M. Holden, S.C. Vogel: Scr. Mater., 2003, vol. 48, pp. 1003-1008.

[21] H. Wang, P. Wu, J. Wang: Int. J. Plast., 2013, vol. 47, pp. 49-64.

[22] P.G. Partridge: Metall. Rev., 1967, vol. 12, pp.169-194.

[23] N. Stanford, M. Barnett: Int. J. Plast., 2013, vol. 47, pp. 165-181.

[24] H. Qiao, S. Agnew, P. Wu: Int. J. Plast., 2015, vol. 65, pp. 61-84.

[25] J. Balík, P. Dobroň, F. Chmelík, R. Kužel, D. Drozdenko, J. Bohlen, D. Letzig, P. Lukáč: Int. J. Plast., 2016, vol. 76, pp. 166-185.

[26] R.V. Mises: J. Appl. Math. Mech., 1928, vol. 8, pp. 161-185.

[27] G.I. Taylor: Inst. Metal, 1938, vol. 62, pp. 307-324.

[28] C.H. Cáceres, P. Lukáč, A.H. Blake: Philos. Mag., 2008, vol. 88, pp. 991-1003.

[29] B.C. Wonsiewicz: Plasticity of magnesium crystals [dissertation], Massachusetts Institute of Technology, Cambridge, 1966.

[30] G.E. Dieter: Mechanical Metallurgy, SI Metric ed., McGraw-Hill Book Company, London, 1988.

[31] A. Staroselsky, L. Anand: Int. J. Plast., 2003, vol. 19, pp. 1843-1864. 
[32] S. Agnew, M. Yoo, C. Tomé: Acta Mater., 2001, vol. 49, 4277-4289.

[33] A. Styczynski, C. Hartig, J. Bohlen, D. Letzig: Scri. Mater., 2004, vol. 50, pp. 943-947.

[34] M. Barnett, C. Davies, X. Ma: Scri. Mater., 2005, vol. 52, pp. 627-632.

[35] M. Barnett: Metall. Mater. Trans. A, 2003, vol. 34, pp. 1799-1806.

[36] S.R. Agnew, Ö. Duygulu: Int. J. Plast., 2005, vol. 21, pp. 1161-1193.

[37] X. Lou, M. Li, R. Boger, S. Agnew, R. Wagoner: Int. J. Plast., 2007, vol. 23, pp. 44-86.

[38] H. Takuda, T. Morishita, T. Kinoshita, S. Shirakawa: J. Mater. Process. Technol., 2005, vol. 164, pp. 1258-1262.

[39] F. Kabirian, A.S. Khan, T. Gnäupel-Herlod: Int. J. Plast., 2015, vol. 68, pp. 1-20.

[40] W. Wang, J. Liu, A.K. Soh: Acta Mech., 2019, pp. 1-16.

[41] G. Proust, C.N. Tomé, A. Jain, S.R. Agnew: Int. J. Plast., 2009, vol. 25, pp. 861-880.

[42] M. Li, X. Lou, J. Kim, R. Wagoner: Int. J. Plast., 2010, vol. 26, pp. 820-858.

[43] H. Wang, P. Wu, C. Tomé, J. Wang: Mater. Sci. Eng. A, 2012, vol. 555, pp. 93-98.

[44] H. Wang, P. Wu, J. Wang, C. Tomé: Int. J. Plast., 2013, vol. 49, pp. 36-52.

[45] H. Zhang, A. Jérusalem, E. Salvati, C. Papadaki, K.S. Fong, X. Song, A.M. Korsunsky: Int. J. Plast., 2019 [article in press].

[46] Y. Wang, J. Huang: Acta Mater., 2017, vol. 55, pp. 897-905.

[47] M. Barnett, O. Bouaziz, L. Toth: Int. J. Plast., 2015, vol. 72, pp. 151-167.

[48] U.F. Kocks: Metall. Mater. Trans., 1970, vol. 1, pp. 1121-1143.

[49] A.V. Nagasekhar, M.A. Easton, C.H. Cáceres: Adv. Eng. Mater., 2009, vol. 11, pp. $912-$ 919.

[50] M. Easton, W. Qian Song, T. Abbott: Mater. Des., 2006, vol. 27, pp. 935-946.

[51] S.M. Zhu, T.B. Abbott, M.A. Gibson, J.F. Nie, M.A. Easton: Mater. Sci. Eng. A., 2016, vol. 656, pp. 34-38.

[52] M.A. Meyers: Dynamic Behaviour of Materials, John Wiley \& Sons, New York, 1994.

[53] T. Sumitomo, C.H. Cáceres, M. Veidt: J. Light Metals, 2002, vol. 2, pp. 49-56.

[54] M. Pekguleryuz, K. Kainer, A. Kaya: Fundamentals of Magnesium Alloy Metallurgy, first ed., Woodhead Publishing, Cambridge, 2013.

[55] M.H. Yoo: Metall. Trans. A., 1981, vol. 12, pp. 409-418.

[56] J.W. Christian, S. Mahajan: Prog. Mater. Sci., 1995, vol. 39, pp. 1-157.

[57] T.W. Duerig, R. Zadno: in Engineering aspects of shape memory alloys, T.W. Duerig, K.N. Melton, D. Stöckel, C.M. Wayman, eds., Butterworth-Heinemann Publisher, Oxford, 1990, pp. 369-393.

[58] O. Muránsky, D.G. Carr, P. Šittner, E.C. Oliver: Int. J. Plast., 2009, vol. 25, pp. 11071127.

[59] Q. Ma, B. Li, A.L. Oppedal, W.R. Whittington, S.J. Horstemeyer, E.B. Marin, P.T. Wang, M.F. Horstemeyer: Mater. Sci. Eng. A., 2013, vol. 559, pp. 314-318.

[60] M.A. Meyers, O. Vöhringer, V.A. Lubarda: Acta Mater., 2001, vol. 49, pp. 4025-4039.

[61] I. Ulacia, N.V. Dudamell, F. Gálvez, F, S. Yi, M.T. Pérez-Prado, I. Hurtado: Acta Mater., 2010, vol. 58, pp. 2988-2998.

[62] C. Bettles, M. Barnett, eds.: Advances in wrought magnesium alloys: Fundamentals of processing, properties and applications, Woodhead Publishing, Cambridge, 2012.

[63] D. Nagarajan, C.H. Cáceres, J.R. Griffiths: in Proceedings of the 12th International Symposium on Physics of Materials, F. Chmelík, R. Král, J.L. Martin, eds., Acta Phys. Polonica A., 2012, vol. 122, No. 3.

[64] D. Drozdenko, J. Čapek, B. Clausen, A. Vinogradov, K. Máthis: J. Alloys Compd., 2019, vol. 786, pp. 779-790.

[65] R.E. Reed-Hill, E.P. Dahlberg, W.A. Slippy Jr: Trans. Met. Soc. AIME., 1965, vol. 233, pp. 1766-1770. 
[66] Y. Cui, Y. Li, Z. Wang, X. Ding, Y. Koizumi, H. Bian, L.Y. Lin, A. Chiba: Int. J. Plast., 2017, vol. 91, pp. 134-159.

[67] H. Mecking, U.F. Kocks: Acta Metall., 1981, vol. 29, pp. 1865-1875.

[68] P.B. Hirsch, T.E. Mitchell, Can. J. Phys., 1967, vol. 45, pp. 663-706.

[69] U.F. Kocks: Philos. Mag., 1966, vol. 13, pp. 541-566.

[70] W.D. Callister, D.G. Rethwisch: Materials Science and Engineering: An Introduction, eighth ed., Wiley, New York, 2007.

[71] J.H. Hollomon: Aime Trans., 1945, vol. 12, pp. 1-22.

[72] H. Kleemola, M. Nieminen: Metall. Trans., 1974, vol. 5, pp. 1863-1866.

[73] P. Ludwik: Elemente des technologischen Mechanik, Verlag von Julius Springer, Berlin 1909.

[74] S. Kleiner, P.J Uggowitze: Mater. Sci. Eng. A, 2004, vol. 379, pp. 258-263.

[75] B. Wonsiewicz, W. Backofen: Trans. Metall. Soc. AIME, 1967, vol. 239, pp. 1422-1433.

[76] S. Agnew, D. Brown, C. Tomé: Acta Materialia, 2006, vol. 54, pp. 4841-4852.

[77] K. Máthis, Z. Trojanova, P. Lukáč, C.H. Cáceres, J. Lendvai: J. Alloys Compd., 2004, vol. 378, pp. 176-179.

[78] H. Wang, P. Wu, S. Kurukuri, M.J. Worswick, Y. Peng, D. Tang, D. Li: Int. J. Plast., 2018, vol. 107, pp. 207-222.

[79] D. Nagarajan, C. Cáceres: Metall. Mater. Trans. A, 2018, vol. 49, pp. 5288-5297.

[80] B. Zhang, A.V. Nagasekhar, T. Sivarupan, C.H. Cáceres: Adv. Eng. Mater., 2013, vol. 15, pp. 1059-1067.

[81] B. Zhang, K.V. Yang, A.V. Nagasekhar, C.H. Cáceres, M.A. Easton: J. Miner. Metals Mater. Soc., 2014, vol. 66, pp. 2086-2094.

[82] K.V. Yang, C.H. Cáceres, M.A. Easton: Metall. Mater. Trans. A, 2014, vol. 45, pp. 41174128.

[83] G. Nayyeri, W.J. Poole, C.W. Sinclair, S. Zaefferer: Scr. Mater., 2018, vol. 156, pp. 3741.

[84] H.J. Bong, X. Hu, X. Sun, Y. Ren: Int. J. Plast., 2019, vol. 113, pp. 35-51.

[85] C. Paramatmuni, A.K. Kanjarla: Int. J. Plast., 2019, vol. 113, pp. 269-290.

[86] H. Asgari, A. Odeshi, J. Szpunar, L. Zeng, E. Olsson, D. Li: Mater. Sci. Eng. A, 2015, vol. 623, pp. 10-21.

[87] H. Asgari, J. Szpunar, A. Odeshi: Mater. Des., 2014, vol. 61, pp. 26-34.

[88] Q. Sun, A. Ostapovets, X. Zhang, L. Tan, Q. Liu: Philos. Mag., 2018, vol. 98, pp. 741751.

[89] B. Zhu, X. Liu, C. Xie, Y. Wu, J. Zhang: Vac., 2019, vol. 160, pp. 279-285. 
786 List of Tables

787

788 Table 1. Parameters in Stage II: $\mathrm{K}_{\mathrm{II}}(\mathrm{MPa})$ and $\mathrm{n}_{\mathrm{II}}$ of best fit of Eq. (4).

789

\begin{tabular}{|c|c|c|c|c|c|c|c|c|c|c|}
\hline \multirow{2}{*}{$\dot{\varepsilon}$} & \multicolumn{2}{|c|}{ AM40 } & \multicolumn{2}{|c|}{ AM60 } & \multicolumn{2}{|c|}{ AZ91 } & \multicolumn{2}{|c|}{ AE44 } & \multicolumn{2}{|c|}{ AE44-T5 } \\
\hline & $\mathbf{K}_{\text {II }}$ & nII & $\mathbf{K}_{\text {II }}$ & nII & $\mathbf{K}_{\text {II }}$ & nII & $\mathbf{K}_{\text {II }}$ & nII & $\mathbf{K}_{\text {II }}$ & nII \\
\hline $10^{-6}$ & $337 \pm 0.84$ & $0.19 \pm 0.00$ & $507 \pm 59.2$ & $0.23 \pm 0.02$ & $1049 \pm 316$ & $0.30 \pm 0.05$ & $794 \pm 61.7$ & $0.30 \pm 0.01$ & $565 \pm 42.9$ & $0.21 \pm 0.02$ \\
\hline $10^{-5}$ & - & - & - & - & - & - & $864 \pm 67.7$ & $0.30 \pm 0.01$ & $679 \pm 0.42$ & $0.23 \pm 0.00$ \\
\hline $10^{-4}$ & $411 \pm 31.6$ & $0.22 \pm 0.01$ & $455 \pm 1.50$ & $0.21 \pm 0.00$ & $591 \pm 148$ & $0.21 \pm 0.04$ & $955 \pm 59.7$ & $0.32 \pm 0.01$ & $714 \pm 25.4$ & $0.24 \pm 0.01$ \\
\hline $10^{-3}$ & - & - & - & - & - & - & $987 \pm 2.17$ & $0.33 \pm 0.00$ & $757 \pm 4.10$ & $0.25 \pm 0.00$ \\
\hline $10^{-2}$ & $412 \pm 1.44$ & $0.21 \pm 0.00$ & $610 \pm 77.7$ & $0.26 \pm 0.02$ & $654 \pm 0.26$ & $0.23 \pm 0.00$ & $898 \pm 5.37$ & $0.31 \pm 0.00$ & $766 \pm 0.11$ & $0.25 \pm 0.00$ \\
\hline $10^{-1}$ & - & - & $638 \pm 2.32$ & $0.26 \pm 0.00$ & $916 \pm 0.07$ & $0.28 \pm 0.00$ & $1369 \pm 1.25$ & $0.37 \pm 0.00$ & $791 \pm 1.47$ & $0.25 \pm 0.00$ \\
\hline Average & $387 \pm 39.5$ & $0.21 \pm 0.01$ & $552 \pm 89$ & $0.24 \pm 0.02$ & $803 \pm 256$ & $0.25 \pm 0.05$ & $978 \pm 190$ & $0.32 \pm 0.02$ & $712 \pm 77.9$ & $0.24 \pm 0.01$ \\
\hline
\end{tabular}

790

791

792

793

794

795

796

797

798

799

800

801

802

803

804

805

806

807

808

809

810

811

812

813

814

815

816

817

818 
819 Table 2. Parameters in Stage III: $\Theta(\mathrm{MPa})$ and $\sigma_{\mathrm{y}, \mathrm{III}}(\mathrm{MPa})$ of best fit of Eq. (5) measured from 820 experimental flow curves.

821

\begin{tabular}{ccccccccccc}
\hline \multirow{2}{*}{$\dot{\boldsymbol{\varepsilon}}$} & \multicolumn{2}{c}{ AM40 } & \multicolumn{2}{c}{ AM60 } & \multicolumn{2}{c}{ AZ91 } & \multicolumn{2}{c}{ AE44 } & \multicolumn{2}{c}{ AE44-T5 } \\
\cline { 2 - 10 } & $\boldsymbol{\Theta}$ & $\boldsymbol{\sigma}_{\mathbf{y}, \text { III }}$ & $\boldsymbol{\Theta}$ & $\boldsymbol{\sigma}_{\mathbf{y}, \text { III }}$ & $\boldsymbol{\Theta}$ & $\boldsymbol{\sigma}_{\mathbf{y}, \text { III }}$ & $\boldsymbol{\Theta}$ & $\boldsymbol{\sigma}_{\mathbf{y}, \text { III }}$ & $\boldsymbol{\Theta}$ & $\boldsymbol{\sigma}_{\mathbf{y}, \text { III }}$ \\
\hline $\mathbf{1 0}^{-\mathbf{6}}$ & $1299 \pm 27$ & $127 \pm 0.4$ & $1334 \pm 33$ & $145 \pm 1.1$ & $2264 \pm 84$ & $180 \pm 3.4$ & $1187 \pm 4.7$ & $142 \pm 1.4$ & $977 \pm 11$ & $169 \pm 4.0$ \\
$\mathbf{1 0}^{-5}$ & - & - & - & - & - & - & $1400 \pm 19$ & $145 \pm 1.0$ & $1203 \pm 2.3$ & $178 \pm 0.6$ \\
$\mathbf{1 0}^{-4}$ & $1437 \pm 16$ & $126 \pm 0.6$ & $1479 \pm 9.6$ & $148 \pm 1.9$ & $2271 \pm 13$ & $185 \pm 1.9$ & $1606 \pm 16$ & $151 \pm 1.3$ & $1435 \pm 8.1$ & $188 \pm 1.3$ \\
$\mathbf{1 0}^{-3}$ & - & - & - & - & - & - & $1645 \pm 5.7$ & $156 \pm 1.3$ & $1555 \pm 2.6$ & $194 \pm 0.9$ \\
$\mathbf{1 0}^{-\mathbf{2}}$ & $1512 \pm 18$ & $131 \pm 2.2$ & $1509 \pm 0.1$ & $147 \pm 0.6$ & $2381 \pm 1.9$ & $188 \pm 0.2$ & $1693 \pm 31$ & $162 \pm 0.5$ & $1601 \pm 17$ & $201 \pm 0.2$ \\
$\mathbf{1 0}^{-\mathbf{1}}$ & - & - & $1512 \pm 32$ & $150 \pm 1.2$ & $2252 \pm 48$ & $190 \pm 0.8$ & $1776 \pm 18$ & $165 \pm 1.4$ & $1728 \pm 9.1$ & $206 \pm 1.9$ \\
\hline
\end{tabular}

822

823

824

825

826

827

828

829

830

831

832

833

834

835

836

837

838

839

840

841

842

843

844

845

846

847

848

849

850

851

852

853

854 
855 Table 3. Parameters in Stage IV: $\mathrm{K}_{\mathrm{IV}}(\mathrm{MPa})$ and $\mathrm{n}_{\mathrm{IV}}$ of best fit of Eq. (14).

856

\begin{tabular}{ccccccccccc}
\hline \multirow{\boldsymbol{\varepsilon}}{*}{} & \multicolumn{2}{c}{$\mathbf{A M 4 0}$} & \multicolumn{2}{c}{ AM60 } & \multicolumn{2}{c}{ AZ91 } & \multicolumn{2}{c}{ AE44 } & \multicolumn{2}{c}{ AE44-T5 } \\
\cline { 2 - 9 } & $\mathbf{K}_{\mathbf{I V}}$ & $\mathbf{n}_{\mathbf{I V}}\left(\mathbf{1 0}^{-\mathbf{3}}\right)$ & $\mathbf{K}_{\mathbf{I V}}$ & $\mathbf{n}_{\mathbf{I V}}\left(\mathbf{1 0}^{-\mathbf{3}}\right)$ & $\mathbf{K}_{\mathbf{I V}}$ & $\mathbf{n}_{\mathbf{I V}}\left(\mathbf{1 0}^{-\mathbf{3}}\right)$ & $\mathbf{K}_{\mathbf{I V}}$ & $\mathbf{n}_{\mathbf{I V}}\left(\mathbf{1 0}^{-\mathbf{3}}\right)$ & $\mathbf{K}_{\mathbf{I V}}$ & $\mathbf{n}_{\mathbf{I V}}\left(\mathbf{1 0}^{-\mathbf{3}}\right)$ \\
\hline $\mathbf{1 0}^{-\mathbf{6}}$ & $373 \pm 1.6$ & $106 \pm 0.8$ & $396 \pm 1.4$ & $97 \pm 2.7$ & $363 \pm 0.6$ & $76 \pm 3.3$ & $347 \pm 1.3$ & $101 \pm 0.8$ & $334 \pm 4.0$ & $73 \pm 0.4$ \\
$\mathbf{1 0}^{-\mathbf{5}}$ & - & - & - & - & - & - & $366 \pm 2.4$ & $92 \pm 1.6$ & $361 \pm 0.5$ & $68 \pm 0.2$ \\
$\mathbf{1 0}^{-\mathbf{4}}$ & $376 \pm 3.6$ & $96 \pm 2.3$ & $399 \pm 3.2$ & $85 \pm 0.5$ & $415 \pm 0.0$ & $97 \pm 0.0$ & $377 \pm 1.0$ & $85 \pm 1.1$ & $385 \pm 1.2$ & $63 \pm 0.2$ \\
$\mathbf{1 0}^{-\mathbf{3}}$ & - & - & - & - & - & - & $389 \pm 5.1$ & $81 \pm 1.2$ & $394 \pm 0.7$ & $59 \pm 0.0$ \\
$\mathbf{1 0}^{-\mathbf{2}}$ & $379 \pm 5.6$ & $95 \pm 0.8$ & $382 \pm 0.9$ & $79 \pm 0.9$ & $410 \pm 0.0$ & $93 \pm 0.0$ & $384 \pm 2.3$ & $72 \pm 1.6$ & $399 \pm 2.6$ & $55 \pm 0.5$ \\
$\mathbf{1 0}^{-\mathbf{1}}$ & - & - & $378 \pm 1.1$ & $74 \pm 0.4$ & $422 \pm 8.3$ & $94 \pm 3.2$ & $389 \pm 1.7$ & $68 \pm 0.0$ & $402 \pm 0.0$ & $51 \pm 0.6$ \\
\hline
\end{tabular}

857

858

859

860

861

862

863

864

865

866

867

868

869

870

871

872

873

874

875

876

877

878

879

880

881

882

883

884

885

886

887

888

889

890 
891

892

\begin{tabular}{cccccc}
\hline \multirow{2}{*}{ Alloy } & \multicolumn{3}{c}{$\mathbf{K}_{\mathbf{I V}=\mathbf{a}\left[\mathbf{1 - b} \dot{\boldsymbol{\varepsilon}}^{\mathbf{c}}\right]}$} & \multicolumn{2}{c}{$\mathbf{n}_{\mathbf{I V}}=\mathbf{d} \dot{\boldsymbol{\varepsilon}}^{\mathbf{f}}$} \\
\cline { 2 - 6 } AM40 & $\mathbf{a}$ & $\mathbf{b}$ & $\mathbf{c}$ & $\mathbf{d}$ & $\mathbf{f}$ \\
\hline AM60 & 385 & 0.011 & -0.069 & 0.088 & -0.0128 \\
AZ91 & 400 & 0.095 & 0.212 & 0.070 & -0.0230 \\
AE44 & 110 & -2.926 & 0.014 & 0.099 & 0.0163 \\
AE44-T5 & 391 & 0.003 & -0.261 & 0.063 & -0.0343 \\
\hline
\end{tabular}

893

894

895

896

897

898

899

900

901

902

903

904

905

906

907

908

909

910

911

912

913

914

915

916

917

918

919

920

921

922

923

924

925 
List of Figures

Fig. 1. Monotonic (dashed) taken from [4] and cyclic (solid) stress-strain behavior of (a) AZ91 and (b) AE44 at different strain rates, $\dot{\varepsilon}=10^{-6} \mathrm{~s}^{-1}$ (top curve) $-10^{-2} \mathrm{~s}^{-1}$ (bottom curve) .

Fig. 2. The applied stress as a function of $\varepsilon_{t}-\varepsilon_{\text {I }}$ strain, for (a) AM40, (b) AM60, (c) AZ91, (d) AE44 and (e) AE44-T5, at strain-rate range $10^{-6}-10^{-1} \mathrm{~s}^{-1}$. The dotted line is the anelastic strain, $\varepsilon_{\mathrm{ae}}$ and the dashed line represents the average of Stage II strain $\varepsilon_{\mathrm{II}, \mathrm{av}}$ which is composed of $60-75 \%$ of anelastic strain. Note that $\varepsilon_{\text {III }}$ and $\varepsilon_{\text {IV }}$ are negligible at such low strains.

Fig. 3. Comparison of (a) the Weibull function [9] and (b) the power-law function in analyzing the stress-anelastic strain relationship in Stage II. Changing the Weibull function parameters is shown to alter the entire function curve, which cannot reflect the strain-rate insensitive and sensitive components of anelasticity.

Fig. 4. Stress when $\varepsilon_{\text {III }}$ reaches 0.01 for AM40, AM60, AZ91, AE44 and AE44-T5 and 0.015 for AZ91 as a function of maximum anelastic stress.

Fig. 5. The experimental stress-strain curves (solid) in Stage II for AZ91 and AE44, as compared with the best fitted curves (dashed) using Eq. (4).

Fig. 6. The experimental flow curves (solid) of (a) AZ91 and (b) AE44 at strain rates $10^{-6}-10^{-1}$ $\mathrm{s}^{-1}$ as compared with the best fitted linear lines (dashed) according to Eq. (5).

Fig. 7. The strain hardening rate, $\Theta$ in Stage III for the studied alloys at different strain rates. The solid filled symbol and dashed line indicate the measured $\Theta$ using Eq. (5) and the modelled $\Theta$ with Eq. (9), respectively. The values of $\Theta_{\mathrm{h}}$ and constants $\mathrm{A}, \mathrm{B}$, and $\mathrm{C}$ for each alloy are shown.

Fig. 8. The <a $>$ prismatic yield stress, $\sigma_{y, \text { III }}$ of present alloys at different strain rates. The solid filled symbol and dashed line indicate $\sigma_{\mathrm{y}, \mathrm{III}}$ measured from experimental flow curves using Eq. (5) and the modelled $\sigma_{y, I I I}$ with Eq. (13), respectively. The value of $\sigma_{y, I I I}(\mathrm{MPa})$ for each alloy is shown.

Fig. 9. The experimental (solid) and the best fitted (dashed) stress-strain curve of Stage IV for (a) AZ91 and (b) AE44. Note the different scales on the x-axis between the two alloys.

Fig. 10. Comparison of Ludwik's and Hollomon's models with $\mathrm{K}_{\mathrm{IV}}$ and $\mathrm{n}_{\mathrm{IV}}$ of best fit of Eq. (14). 
969 Fig. 11. (a) An example of the experimental (solid) and modelled (dashed) stress-strain curves

970 showing the contributions of strain for each of the stages of deformation, with each of the

971 stages adding onto the previous stages of strain as per Eq. (1). (b) The individual contributions

972 of strain for each of the stages of deformation for AE44 as shown in (a).

974 Fig. 12. Comparison of experimental (coloured) and modelled (black dashed) stress-strain 975 curves of (a) AM40, (b) AM60, (c) AZ91, (d) AE44, and (e) AE44-T5 at wide strain-rate range $97610^{-6}-10^{-1} \mathrm{~s}^{-1}$. 